Tafel XVII.

Fig. 5. Metastatische lymphosarcomatöse Knötchen in der Milchdrüse. a Erweiterte Alveolen und Cysten. b Ein mit runden Zellen angefüllter Alveolus, dessen A usführungsgang obliterirt ist. c Ausführungsgänge, an einzelnen Stellen verengt. a Interstitielles Bindegewebe, mit runden Zellen infiltrirt. e Riesenzellen und Rundzellen theils im reticulären, theils im faserigen Bindegewebe. f Ein obliterirtes Blutgefäss.

Fig. 6. Lymphosarcomatöses Knötchen im interstitiellen Bindegewebe. a Riesenzellen. b Rundzellen im reticulären Bindegewebe. c Ein verengter Ausführungsgang und Alveolen.

Fig. 7. Ein lymphosarcomatōses Knötchen: a Riesenzellen mit einander und mit dem Reticulum durch Ausläufer verbunden. b Reticularbindegewebe mit sternförmigen und runden Zellen, c Ein verengter Alveolus.

Fig. 8. Isolirte Zellen aus der Milchdrüse der Kuh mit metastatischen lymphosarcomatösen Knötchen. a Bindegewebszellen und Uebergangsformen derselben in die Riesenzellen. b Kugelförmige und unregelmässig geformte Riesenzellen mit zwei und mehreren Kernen.

\title{
XXXII.
}

\section{Beiträge zur systematischen Botanik der pflanzlichen Parasiten mit experimentellen Untersuchungen über die durch sie bedingten Krankiheiten.}

\author{
Von Dr. Paul Grawitz, \\ Assistenten am pathologischen Institut zu Berlin.
}

(Hierzu Tôf. XVIII - XIX.)

Die Frage nach den Lebensbedingungen und der physiologischen Bedeutung derjenigen niederen chlorophyllfreien Pflanzen, welche auf der oberfläche oder im innern thierischer Gewebe wuchernd gefunden werden, hat seit den ersten einschlägigen Beobachtungen immer ein zwischen der Pathologie und der botanischen Wissenschaft streitiges Grenzgebiet dargestellt. Dem entsprechend weist die Literatur in den Arbeiten über pflanzliche Parasiten zwei wesentlich von einatider verschiedene Reihen von Untersuchungen auf. Medicinischerseits genügte meistens der entweder constante oder doch sehr bäufige Befund von Pilzvegetationen bei einer Anzahl von Erkrankungen der Haut und der Schleimhäute zu dem 


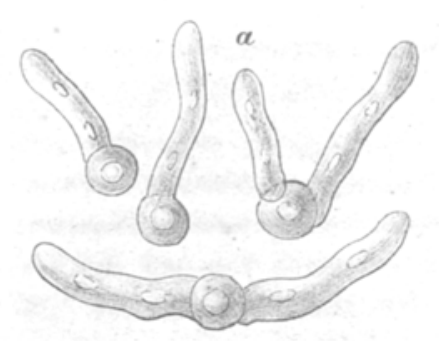

Fig. 1.

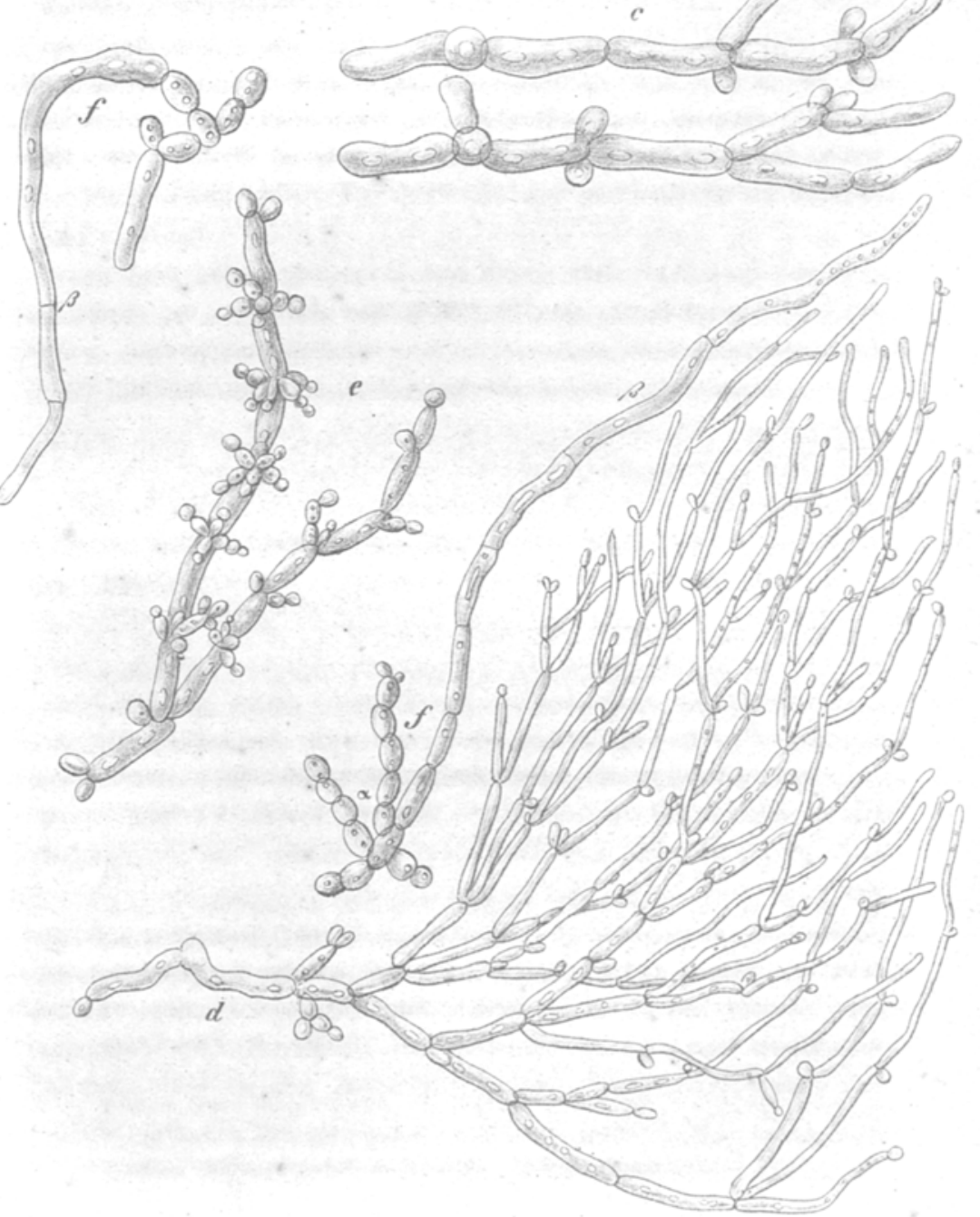




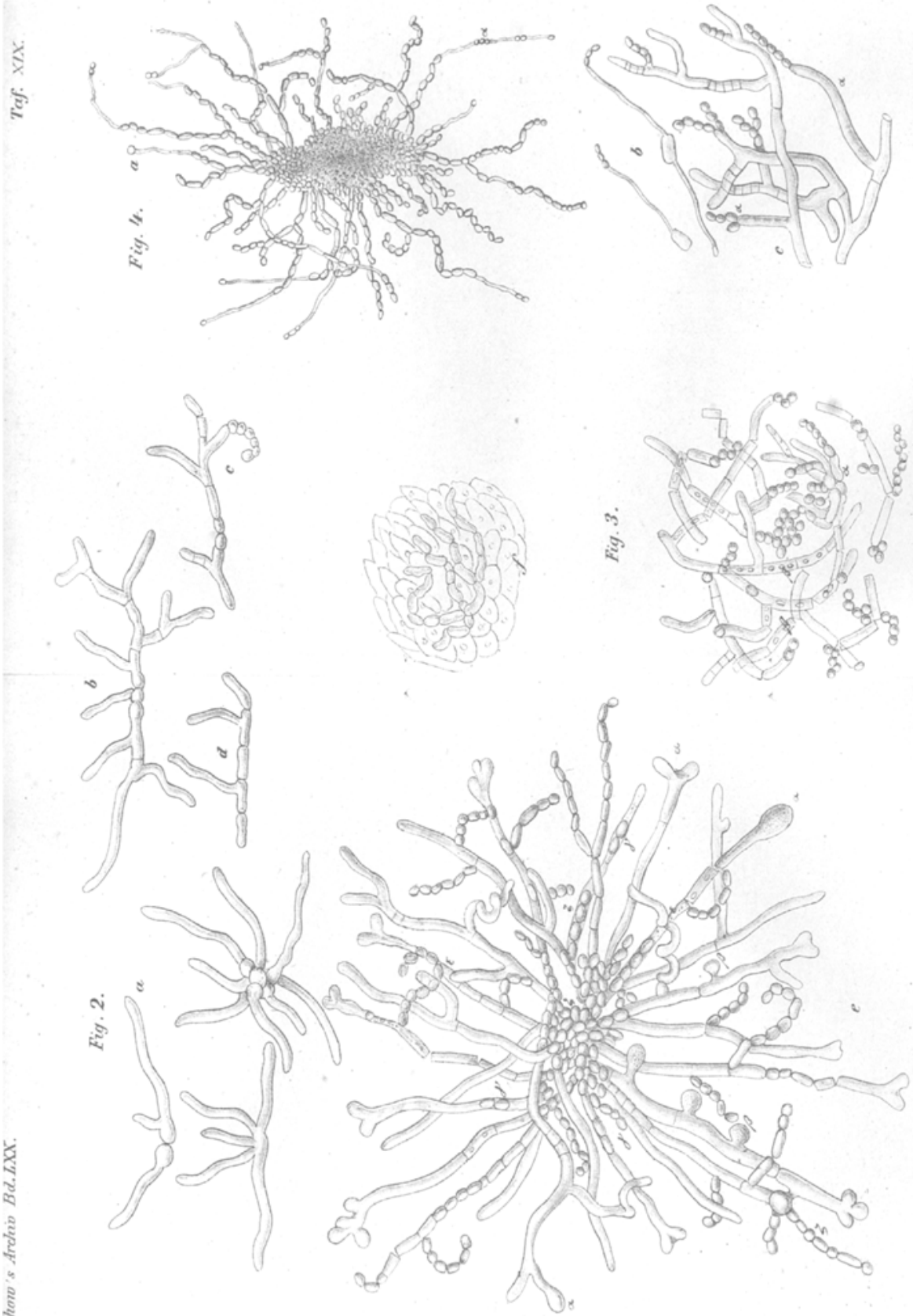


Schlusse, dass diese Pilze als die erste Ursache der Affection anzusehen seien, und das Interesse concentrirte sich dann auf die genauere Erforschung der pathologischen Vorgänge, welche aus dem Wachsthum jener Parasiten durch die Reaction des Organismus hervorgingen. Blieben dennoch Zweifel an der Frage, ob der Pilz wirklich den ersten Anstoss zu der Krankheit gegeben habe, so wurden Uebertragungsversuche z. B. mit Favusborken, welche erweicht und auf die Haut eingerieben wurden, oder mit Epidermisschuppen einer von Herpes oder Pityriasis versicolor befallenen Hautstelle gemacht, in der Regel ein Verband darüber befestigt, und abgewartet, welche Veränderungen die so behandelte Haut eingehen würde. Die Resultate dieser Versuche sind von einander vielfach abweichend und sich widersprechend; nur darin stimmen Alle überein, dass, sofern der Erfolg ein positiver war, die Pilze die Causa efficiens seien. Ist auch diese Methode wenig geeignet, um ein exactes Bild von den genaueren Vorgängen zu geben, in welchen pflanzliche und thierische Zellen hier einander gegenüberstehen, ob die unverletzte Haut oder das mit übertragene Secret den ersten Nâhrboden für den Schmarotzer abgeben, so blieb doch die Deutung immer innerhalb gewisser controlimbarer Grenzen, und nabm nicht jene schrankenlosen ungeheuerlichen Gestalten an, zu welchen die - Botaniker in dieser Frage gelangten. In jener unlängst abgeschlossenen Zeitperiode, als die Lehre von der Pleomorphie der Pilze die Mycologie oder doch deren Tagespresse beherrschte, als Hallier, Hof fmann und Alle, welche mit deren Methode untersuchten, jedweden Hyphomyceten aus Hefe, Mikrococeen oder den Sporen anderer Pilze hervorwachsen liessen, da sind auch die Parasiten der menschlichen Pathologie demselben allgemeinen Schicksale verfallen. In der „Dunströhre“ Hoffmann's und den Culturfeldern Hallier's sah man aus ihnen bald Hefe bald Mikrococcus sich bilden, und es giebt kaum einen der bekannten Schimmelpilze, welcher nicht schon angeschuldigt worden wäre, der specifische Parasit der einen oder der anderen Hauterkrankung zu sein.

Für die Mycologie ist diese Epoche jetzt vollkommen vorüber, sie hat nur noch ein historisches Interesse seit durch die exacten Untersuchungsweisen von Tulasne, de Bary und besonders Brefeld all die Schattenbilder eine feste bestimmte Gestalt angenommen haben, seit es gelungen ist, eine einzige Spore in 
durchsichtiger Nährflüssigkeit keimèn zu lassen, und so auf dem Objectträger die Mycelbildung, die Anlage der Fruchtträger und das Reifen der Gonidien obne Unterbrechung Schritt für Schritt zu verfolgen.

Diesen Errungenschaften ist die Pathologie bisher nicht gefolgt, und es soll nun die Aufgabe dieser Zeilen sein, mit Zugrundelegung einer zuverlässigen Untersuchungsmethode die Morphologie und das physiologische Verbalten der auf und in thierischen Geweben lebenden Fadenpilze von Neuem zu prüfen.

Soviel es mir möglich geworden mich auf dem Gebiete der auf Pflanzen lebenden Parasiten zu orientiren, so scheint es sich dort um drei ihrem Wesen nach verschiedene Arten zu handeln:

Erstens giebt es Pilze, welche nur und ausschliesslich als Parasiten, $d . h$. in den Geweben lebender Pflanzen vorkommen. Sie haben vielfach besondere Angriffsorgane - Haustorien - mit welchen es ibnen möglich wird die Wände der fremden Zellen zu durchbrechen, - Einrichtungen, welche oft lebhaft an die Saugnäpfe thierischer Entozoen erinnern -; sie machen ihren ganzen Entwickelungsgang von der Keimung der Sporen bis zur Fruchtbildung im Innern ihres Wirthes durch, und sind auf keine Weise ausserbalb desselben in künstlichen Nährflüssigkeiten zu cultiviren.

Die zweite, physiologisch durchaus von diesen eigentlichen Parasiten verschiedene Klasse unfasst Pilze, welche auf abgestorbenen organischen Körpern, demnach auch in künstlichen Nährsubstraten gedeihen, dabei aber im Stande sind, sobald sie auf geeignete, übrigens vollkommen gesunde und lebende Pflanzentheile fallen, dort $\mathrm{zu}$ wachsen und sogar den allmählichen Untergang ihres Wirthes herbeizuführen.

Wiederum anders verhalten sich drittens gewisse Pilze, welche wie die eben erwähnten gewöhnlich als Saprophyten leben, und keine unversebrten Pflanzentbeile angreifen können, wobl aber im Stande sind, Pflanzen, oder besonders deren Früchte als Parasiten zu befallen, wenn irgendwo eine Wunde oder Verletzung der Oberfläche ihnen den Weg zu den weicheren saftigen Parenchymzellen frei legt. Sie sind ganz unschuldige Schimmelpilze, welche nur durch besonders günstige Gelegenbeiten, wie die eben genannten, einmal als zerstörende Schmarotzer auftreten ${ }^{3}$ ).

1) Vgl. Brefeld's Vortrag in der bot. Gescht. zu Berlin 1876. Ueber den Fäulnissprozess schadbaft gewordener Früchte. S. A, 
Es soll nun zunächst versucht werden, der oben angedeuteten Aufgabe gemäss nach den von Brefeld aufgefundenen Culturmethoden die einzelnen krankheiterregenden pflanzlichen Parasiten rein zu züchten, mit den reinen Pilzgonidien durch Uebertragung die entsprechenden Affectionen zn reproduciren, und dann nach ihrem physiologischen Verhalten eine Klassificirung der in Betracht kommenden Fadenpilze aufzustellen.

Beginnen wir mit dem Soor:

Entnimmt man der Mundhöhle eines lebenden Kindes eines jener stecknadelknopfgrossen grauweissen, von rothem Hofe umgebenen Häufchen, welche die jüngsten Stadien der Sooreruption repräsentirea, so findet man darin unter dem Mikroskope:

1) Epithelien.

2) Schizomyceten verschiedener Art.

3) Hefezellen entweder isolirt, oder mit jungen Knospen, den späteren Tochterzellen, versehen, oder in Form ganzer semmelartig an einander gereihter Colonien, der sogenannten Sprossverbände.

4) Mycelien verschiedener Schimmelpilze - ich habe mehrere Pleosporagattungen, Oidium lactis, Mucor mucedo und Andere theils wohl erhalten, theils in abgestorbenen Fragmenten darin gefunden, welche sich gewöhnlich auf den ersten Blick unterscheiden von dem

5) eigentlichen Soorpilze.

Aus dem späteren Verlauf dieser Abhandlung wird hervorgeben, mit welchem Rechte ich einen Gegensatz aufstelle zwischen den anscheinend gleich berechtigten Mycelien der unter 4 erwähnten Schimmelarten und dem des Soorpilzes selbst; - für jetzt mag nur gesagt sein, dass die ersteren zwar sehr häufig, aber doch nicht gradezu constant angetroffen werden, und deshalb schon von vorn herein nicht die Beachtung verdienen, welche uns das ganz regelmässige und stets gleichartige Vorkommen des jetzt zu besprechenden Soorpilzes abnöthigt.

Es würde Wiederholungen verursachen, wollte ich an dieser Stelle eine ausführliche Darstellung derjenigen Formen geben, unter welchen der in Frage stehende Pilz in den Soorhäufchen zur Erscheinung bommt, da derartige Beobachtingen weit besser und schneller am frischen Object als nach Zeichnung und Beschreibung zu machen sind, während diese Zeilen vor Allem der Entwicke- 
lungsgeschichte und der physiologischen Dignität der Pilze gewidmet sind. Beginnen wir also mit den Culturversuchen:

Die vielfachen und sehr umständlichen Vorbereitungen, als da sind das Auskochen und sorgfältige Trocknen der Schälchen, Objectträger und eventuell der Deckgläser, das Glühen der Nadeln, Reinigen des Objectträgerstatifs, der Glasglocke, welche die Gulturen vor Staub schützen soll, u. s. w. darf ich hier wohl füglich zu erörtern unterlassen, da einerseits exacte Vorschriften hierüber von Brefeld $\mathbf{d}^{\mathbf{}}$ ) existiren, und da andererseits zur Zeit des Bakteriencultus die genannten Verfahren des Oefteren besprochen worden sind.

Als Nährflüssigkeit bediente ich mich: entweder einer Art von Pasteur'scher Lösung, welche so dargestellt wurde, dass in eine Traubenzuckerauflösung von sebr verschiedener Concentration etwa 1 pCt. weinsteinsaures Ammoniak und etwa 2 pCt. mineralischer Salze, gewonnen durch das Auslaugen gewöhnficher Cigarrenasche, zugesetzt wurden. Das Ganze ward gekocht und filtrirt, abermals gekocht, und dann behufs Cultivirens auf den Objectträger gebracht. Diese Nährflüssigkeit verdunstet sebr lejcht, und kann deswegen nur auf kür'zer dauernde Objectträgerculturen verwendet werden, wenn man nicht öfters einen frischen Tropfen zusetzen will; sehr vortrefflich dagegen eignet sie sich zu den später zu besprechenden Massenculturen.

Ein Decoct von gebackenen Pflaumen, das klar filtrirt und zu Syrupsconsistenz eingedickt worden ist, leistet zwar der Verdunstung besseren Widerstand, konnte indessen in dieser Concentration nicht mit Vortheil verwendet werden, da ganz regelmässig schon innerhalb 18 Stunden das garze Gesichtsfeld mit Hefezellen in dichter Lage bedeckt erschien, ohne dass irgendwo Fäden sichtbar wurden. Mit Wasser oder Pasteur'scher Lösung in Verhältniss von 1:1 verdünnt ist es eine ausgezeichnete Culturflüssigkeit. Mindestens ehenso zweckmässig erwies sich Johannisbeergelee, welcher aus denselben Gründen etwas verdünnt werden musste.

Nimmt man nun von einer dieser Flüssigkeiten zwei grosse Tropfen auf einen sauberen Objectträger, und vertheilt darin eine mit der Nadelspitze entnommene ganz kleine Probe der weissen Soormasse, welche von einem möglichst frischen Schleimhautbelag genommen ist, so findet sich nach 24 Stunden folgendes Bild:

1) Brefeld, Würzb. Verhand. 1873. 
Das ganze Gesichtsfeld, das man jetzt durch Auflegen eines Deckglases auch slärkeren Vergrösserungen zugängig macht, wird durchwandert von lebhaft sich bewegenden Bakterien. Die Hefezellen bedecken, meist in dichten Haufen bei einander liegend, grosse Stellen des Culturfeldes; je grösser der Zuckergehalt des Nährtropfens war, um so reichlicher die Hefezellenagglomerate, je mehr die Zuckermenge hinter den organischen und mineralischen Salzen zurückstand, um so zahlreicher finden sich die kettenartigen Sprossverbände und Fadenpilze. Hier und da entpuppt sich eine jener runden Pflanženzellen, welche am Tage vorher noch kaum von der Hefe oder deren etwa abgebrochenen Knospen zu unterscheiden war; durch einen langen, oft mit Seitensprossungen versehenen Keimling als Gonidienzelle eines Schimmelpilzes. Je nächdem diese ersten Fäden ungegliedert, oder mit kleinen querstehenden Scheidewầnden versehen sind, zeigen sie bereits in diesem jüngsten Wachsthumsstadium, ob sie der Klasse der niederen Pilze angehören, oder ob aus jhnen sieh das viejzellige Mycelium eines der böheren Pilze hervorbilden wird. Beides babe ich vielmals beobachtet. - Hat man nehmlich die Cultur ohne ein Deckglas bei schwacher Vergrösserung ${ }^{1}$ ). angesehen, so gelingt es leicht mit einem Stückchen Fliesspapier den ganzen Culturtropfen bis auf den Keimling wegzusaugen, so dass man denselben dann in einem zugesetzten neuen Tropfen ${ }^{2}$ ) weiter züchten kann. So erhäll man das eine Mal einen Mucor, das andere Mal Penicillium gl. oft eine oder die andere Pleospora-Art, welche man mit aller Genauigkeit aus dem immer weiter sich verbreitenden Keimling bis zur Anlage der Frucbuttäger und der Ausbildung reifer Gonidien sich entwickeln sieht.

Was wird nun aus dem vorher wegen seines constanten Vorkommens als "eigentlichen Soorpilz" bezeichneten Fadenpilze, aus dem Oidium albicans der Autoren und Lehrbücher?

1) Am empfehlenswerthesten ist von den Hartnack'schen Linsen No. 5 0c. III, we]che bei eingescbobenem Tubus ein gates Vebersichtsbild giebt und bei ausgezogenem Tubus genïgende Details erkennen lässt, ohne dass die Linse den unbedeckten Tropfen berührt.

2) Es ist auf das Peinlichste darauf zu achten, dass dieser neue Tropfen dieselbe Concentration bat, als der ursprüngliche, da jede kleine Aendernng in den Bedingungen der Endosmose ein Absterben des zarten Keimlings nach sich zieht. 
Dass die Pilze in den angegebenen Näbrflüssigkeiten fortlebten, das beweist das auch für den wenig geübten Untersucher bemerkbare frische zarte Aussehen, der weiche Contour und der homogene Inhalt der Fäden, welche ich zur Entwickelung angestellt hatte. War das Nährsubstrat zu concentrirt, oder allzu arm an Zucker und Salzen, so ist schon nach 24 Stunden mit aller Entschiedenheit zu sehen, dass die Fäden abgestorben sind. Ihre Contouren werden dann hart und unregelmässig zackig, das Protoplasma zieht sich in Körnerform auf einzelne Abschnitte zusammen, welche dunkler erscheinen, während zwischen ihnen die Zellmembran, als leere Scheide, zurückbleibt; die zarten Vacuolen sind wenig oder gar nicht mehr sichtbar, sie sind in glänzende Löcher verwandelt, der ganze Faden ist dünner und stärker lichtbrechend geworden. Verräth also schon eine oberflächliche Musterung der Cultur nach 24 Stunden, ob der Soorpilz lebend oder todt ist, so lässt sich im günstigen Falle auch sein Wachsthum leicht feststellen. Hierzu ist es unumgänglich nothwendig, eine möglicbst genaue Zeichnung von den Fäden jeder einzelnen Objectträgercultur vorher zu machen. Ein Vergleich der gestern angefertigten Zeichnung mit dem heutigen Objecte erweist dann unmittelbar den etwajgen Fortschritt im Wacbsthum, und ich kann versichern, dass derselbe oft in 24 Stunden ein so rapider ist, dass man seinen eigenen Abbildungen misstraut, wenn man nicht ganz sorgfältig durch Etiquets die Identität der Objecte und der Zeichnungen festgestellt hat.

Nachdem die Thatsache, dass der Soorpilz in einer Nährflüssigkeit überbaupt zur Fortentwickelung gelangt, ausser Zweifel ist, und damit ein sehr wichtiger Gesichtspunkt seiner Stellung in der Reihe der Parasiten gewonnen ist, da tritt in dem Fortgange der Objectträgerzïichtung die Aufgabe an uns heran, den Pilz von den ihm anhängenden Hefen und Schizomyceten zu befreien und ihn einer isolirten Beobachtung zu unterziehen. Diese nicht ganz leichte Aufgabe habe ich nun, wie folgt, gelöst ${ }^{1}$ ):

1) Wenn ich auch für den concreten Fall der Anleitung meines botanischen Lehrers Brefeld entbehrte, so wird man doch unschwer das Princip seiner Methoden, wie er es 1 . c. und in seinen Heften über Schimmelpilze (Leipzig bei Arthur Felix) bekannt gemacht, darin wiedererkennen. 
Dasjenige Häufchen, welches das üppigste Wachsthum der Soorfäden zeigte, wurde durch Ansaugen der Nährflüssigkeit durch Fliesspapier trocken gelegt, dann durch Zusatz neuer Nährlösung rom dem Objectträger emporgehoben, und mit einer Nadel auf einen anderen Objectträger in wiederum frische Nährmischung übertragen. Dort zerzupft musste nun das Häufchen die Aussaat für 4-6.0bjectträgerculturen abgeben, von denen gewöhnlich schon eins am nächsten Tage bakterienfrei gefunden wurde. Jedenfalls wurde mit dem relativ reinsten dieser 6 Culturen die Procedur des Uebertragens der nur mikroskopisch sichtbaren Fäden wiederholt, wodurch im ungiinstigsten Falle nach einer dritten Umpflanzung rollkommen bakterienfreie objecte gewonnen wurden. Trotz allergrösster Sorgfalt konnte beim Uebertragen selbst eines einzelıen kleinen Fädchens nicht immer garantirt werden, dass die Nährtropfen hefefrei blieben, und besonders stellte sich heraus, dass beim Anlegen der sogenanten Massenculturen immer nur in den rel. zuckerarmen Flüssigkeiten überwiegend oder allein Fäden entstanden, während die sehr zuckerhalligen Lösungen grösstentheils Hefe trugen. Es war mir dies um so fataler, als es mich gegen die besten meiner Objectträgerculturen argwöhnisch machte, welche mir die Aussaat für die in Schälchen und Stehkolben mit den oben genannten Nährlösungen angestellten Massenculturen lieferten. Diese letzleren blieben oft wochenlang vollkommen klar und weingelb, ich habe hunderte von Präparaten bei stärksten Vergrösserungen untersucht, ohne ein Bakterium zu finden, nie schlich sich das zudringliche Penicillium in diese abgeschlossenen Soortreibhäuser ein, und dennoch waren aus den sehr zuckerreichen Gläsern die hefeartigen Zellen nicht fernzubalten.

Dieses Räthel erfubr nun seine Lösung, als ich an den mittlerweile sehr zahlreich gewordenen Culturen die Entwickelung des Pilzes und seine Morphologie zu beachten begann:

Bei a in Fig. 1 sieht man den Beginn des Wachsthums. Aus der noch deutlich als rundes Knöpfchen erkennbaren Spore ist ein kurzer Keimschlauch hervorgewachsen, welcher stumpf abgerundet endet. Die nächste Stufe der Entwickelung zeigt der kleine Keimschlauch $b$, aus dessen Spitze ein längsovaler Spross berausgetreten ist, welchen eine Scheidewand von dem ersten Fadengliede trennt. Dieser Spross streckt sich bei c zu einer längeren Zelle, welche 
nicht allein an ihrer Spitze, sondern auch seitlich neue Knospen aussendef; jede dieser kann wiederum zu einer vermehrungsfähigen Zelle auswachsen. Dies geschieht, d. $h$. die Verzweignng wird um so grösser, die einzelnen Zellen um so länger, je diluirter, namentlich je zuckerărmer đie Nährflüssigkeit ist. - Mit einer wabren Hast durchmisst der Pilz in Janggestreckten dunnen Fäden $d$ einén derart diluirten Culturtropfen und nur hier und da wird ein kleines Seitenknöspchen, der Luxus einer Propagationszelle, gebildet. Erhält er keinen Zuschuss an Zucker, so währt es nicht lange, $36-48$ Stunden und die vorher zwar dünnen, aber doch homogenen lichten Zellen werden glänzend und bröcklig, erhalten harte Contouren und grosse zahlreiche Vacuolen - sie sterben ab.

War der Nährboden zuckerreicher, oder wenigstens die absolute Menge des Zuckers grösser, wie es bei den Massenzüchtungen in den Glasschälchen der Fall war, so zeigten die Präparate sehr reichlich Formen, wie die bei e aufgezeichneten. Die kurzen Glieder sind mit zahlreichen, oft zu dichten Trauben an einander liegenden runden Knospen besetzt; da, wo die meisten derselben abgefallen sind, sieht man, wie die erste, aus dem Hauptgliede seitlich abgehende Knospe längsoval gestaltet, einen Ansatz macht, gleichfalls in die Lănge sich za strecken, und einen Zweig zu bilden, wie aber aus iłrer Spitze so viele neue Knöspchen abgehen, dass ihr Protoplasma offenbar nicht ausreicht, für sie die Kosten der Längsdehnung zu bestreiten. Die Hauptkraft des Zelleninhaltes wird hier zur Bildung der Gonidien, ein geringer Bruchtheil zum Ausbau des Pilzkörpers selbst verwendet.

Noch weit schärfer tritt dieses Wachsthumsprincip hervor, wenn die Cultur in ganz stark zuckerhaltigen Flüssigkeiten, z. B. in dem vorher erwähnten syrupdicken Pflaumendecoct gemacht wurde. Hier bildet eine Zelle 4,6, 8 Seitenknospen, diese letzteren wieder Secundärknospen, und, wenn man nicht ganz genau oder viele Bilder durchmustert, so glaubt man nichts als Hefenknospungen und Hefensprossverbände vor sich zu haben, und wirft die Cultur als unbrauchbar bei Seite. Ich gestehe gern zu, dass ich bej der Betrachtung dieser Zellenhaufen kaum im Stande sein würde, zu entscheiden, ob Hele, ob Soorpilz vorliegen, obgleich die eigentliche Hefe sich durch grössere und mehr ovale Zellen von den kleineren und runden Soorsprossungen auszeichnet, und doch ist der wahre 
Sachverhalt unschwer bei genetischer Betrachtung zu erkennen. An Bildern, wie f Fig. 1 sieht man aus einer Mutterzelle nach 5 verschiedenen Richtungen Tochterzellen abgeben, von denen eine einzige länglich ausgezogen ist, während die übrigen 4 rund gestaltet, und mehrfach mit den bekannten semmelartigen Zellenreihen gekrönt sind. An den länglichen Spross schliessen sich nach einander mebrere, immer länger werdende Zellen an, und wir haben so an einem Individuenstock, einen Abschnitt $\alpha$, welcher völlig den Gesetzen der Hefenbildung folgt, einen anderen $\beta \beta$, welcher sich nach dem Typus der höheren scheidewandführenden Thallophyten entwickelt. Derartige, sehr mannichfach gestaltete Uebergangsformen findet man um so bäufiger, je mebr Zucker in dem Nährsubstrat bereits verbraucht ist, und wenn man eine zuckerreiche Massencultur nur lange genug stehen lässt, so überzeugt man sich, dass man vollkommen rein gezüchtet bat, denn aus zahllosen der hefenartigen Knospen sind die stolzesten reich verzweigten Soorfäden hervorgewachsen.

Wir haben somit bereits zwei ibrem Aussehen nach identische, ihrer Genese nach verschiedene Vermehrungszellen des Soorpilzes nachgewiesen, - die an den Fäden hervorgewachsenen Seitenknospen und die befenartigen Zellen, - und wenngleich die Mycologie nicht arm ist an Beispielen für solche mehrfache Gonidienbildung, so ist doch bei keinem anderen Pilze so genau die Abhängigkeit der jeweiligen Modification von ganz bestimmten chemischen Bedingungen bekannt, als diese für den Soorpilz in dem Zuckergebalt des Nährbodens durch diese meine Untersuchungen klar gelegt sind. Die grössere oder geringere Menge Zuckers bestimmt nicht nur Zahl and Bildungsmodus der Gonidien, sondern die ganze Wachsthumsrichtung und Gestalt des Pilzes selbst.

Doch wir sind mit der Entwickelung erst auf der Acme angekommen, und es erübrigt auch bei dem langen Zeitraum der Decadenz einen Augenblick zu verweilen. Hat eine Cultur durch Wochen und Monate sorgfältig geschützt gestanden, ist der Salzund Zuckergebalt der Flüssigkeit demnach bis auf Spuren verbraucht, so gewahrt man an Gonidien wie an den Fäden eine Reihe rückschreitender Veränḍerungen. Die runden und länglichen Zellen hellen sich auf, werden homogen, verlieren die glänzenden Körnchen in ibrem Innern, und gehen einer wirklichen Auflösung ent- 
gegen. Dasselbe begegnet den Fäden, welche in Masse jene Ejgenschaften tragen, welche wir schon mebrfach als den abgestorbenen Mycelien eigenthümlich aufzählten.

Ein kleiner Theil nur entgeht dem Untergang, denn einen spärlichen Rest von Leben rettet der Pilz in die feste Verschanzung von - Dauersporen. Es sind dies keine ganz neuen Anlagen, sondern nur Producte einer Umwandlung, die sich an den Seitenknospen der Pilzfäden vollzieht. Diese meist runden Zellen concentriren ihr homogenes zart durchscheinendes Protoplasma zu einer stark lichtbrechenden centralen Kugel, welche von der ursprünglichen Zellmembran durch eine bald ganz schmale, bald breitere Zone leicht granulirten oder auch homogenen, jedenfalls weit weniger glänzenden Protoplasmas getrennt bleibt. Ob dieser Schicht eine besondere Bedeutung beizumessen ist, ob sie vielleicht bei der späteren Auskeimung dieser Dalıersporen durch ihre Quellung dazu beiträgt, die Zellenmembran zu sprengen, darüber mag die bewährte Erfahrung eines Mycologen von Fach entscheiden. Ich habe lediglich gefunden, dass die Gonidien in diesem Dauerzustande lange ihre Keimkraft bewahren, und dass aus ihnen, nachdem die Zellhülle geplatzt ist, in derselben Weise hefenarlige Knospungen oder lange Fadenzellen hervorspriessen, wie diese Vorgänge für die gewöhnlichen Propagationszellen beschrieben worden sind.

Die voraufgegangene morphologische Darstellung, welche eine so auffallende Achnlichkeit des Soorpilzes mit der gewöhnlichen Culturhefe ergiebt, führt zu der Prüfung der naheliegenden Frage, ob zwischen beiden Pilzarten auch die physiologische Uebereinstimmung der Gäbrungserregung bestehe. In der That ist die Einleitung einer alkoholischen Gährung in zuckertaltigen Flüssigkeiten eine ganz constante Erscheinung, welche das Wachsen des Soorpilzes um so bemerkbarer begleitet, je stärker der Zuckerzusatz in dem Culturtropfen gewählt wird, je ausgesprochener also der Pilz selbst den Keimungstypus der Hefe annimmt.

Wenn ich es wage, auf Grund meiner Züchtungen die bisher gebräuchliche Bezeichnung des Soorpilzes, als Oidium albicans anzugreifen, und ihm seinen Platz in der Systematologie der Kryptogamen an einer anderen Stelle anzuweisen, so darf ich mich dabei auf das Urtheil Brefeld's berufen, welcher mehrfach Proben meiner 
Massenculturen untersucht, und diese für vollkommen rein anerkannt hat. Der Einwurf, dass das Hefestadium etwa einem anderen Pilze angehöre, als die Mycelien, fällt hiermit fort, und daraus folgt, dass der Soorpilz mit dem Oidium lactis durchaus nichts zu thun hat. Die Gonidien und Fäden des letzteren sehen denen des Soorpilzes zwar oft zum Verwechseln ähnlich, bekanntlich steht die Grösse derselben in solcher Abhängigkeit zu dem Nährboden, dass sie häufig doppelt und dreifach so üppig sind in reicher, als in sehr kümmerlicher Nahrung; der einzig sichere Maassstab liegt aber in der Fruchtbildung. Das Oidjum treibt gegliederte Fäden, welche in eine Reihe kurzer Abschnitte sich theilen, wobei ein jeder derselben nach dem Auseinanderfallen aus dem Verbande als selbständige Gonidie weiter keimt. Die Fäden des Soorpilzes entstehen dagegen aus Sprossen, ihre Gonidien sind an Knospen, wie jene der Hefe, und niemals findet eine Abschnürung der Spitze, nie eine nachträgliche Gliederung an einem einmal gebildeten Faden statt. Dieser Modus der Vermehrung kommt vielmehr der Klasse der Mycodermen zu, und die Klassificirung des Soors würde eine leichte Entscheidung finden, wenn nicht die scheidewandführenden Mycelien eine vorsichtige Prüfung erforderten, ob er nicbt unter die höberen Pilze zu stellen sej. Aus den Zweifeln über diesen Punkt, weleher sonst in der mycologischen Literatur keine eingehende Erörterung erfährt, soviel mir bekannt geworden, befreit mich eine Arbeit Cienkowski's über „Die Pilze der Kahmhaut" ${ }^{61}$ ). In derselben bespricht er die Mycoderma vini (Desm.) und die ihr nahe verwandte Chalara, und bis auf einige Einzelheiten stimmen Beschreibung und Abbildungen so genau mit den verschjedenen Phasen des Soors überein, dass ich an der Idertität des letzteren mit der Mycoderma vini nicht wobl zweifeln möchte. Bilder wie Fig. 1e meiner Tafel sind Cienkowski zwar anscheinend nicht vorgekommen, indessen ist dieser Umstand nicht befremdend, da seine Culturen in zuckerfreien, meist stark sauren Flüssigkeiten (Sauerkraut und Gurkensaft, Wein, Bier, Milch etc.) angestellt wurden. Dass er der Dauersporen nicht erwähnt; liegt wobl daran, dass er kein rein cultivirtes Material längere Zeit aufbewahrt hat, ebenso wie mir der Vorgang einer endogenen Zellen-

1) Cienkowski, Die Pilze der Kahmhant. Mélanges biologiques tirés du bulletin de l'acad. imp. des sciences de St. Petersbourg. Tom. VIIl. 
bildung entgangen ist, den ich auch hier nicht weiter urgiren will, um über dem botanischen Detail nicht das pathologisch Wichtige zu vernachlässigen.

Mit dieser Thatsache, dass der Soorpilz vollkommen identisch ist mit einem der gemeinsten Kahmpilze, der auf einer Menge der verschiedensten Flïssigkeiten, namentlich verdorbener Fruchtsäfte spontan auftritt, und daselbst Gährungen hervorruft, ist natürlich die enorme Verbreitung der durch ihn bedingten Affection erklärt. Es ist ebenso die alkoholische Gährung, welche bisher auf Rechnung der Hefe gesetzt wurde; nunmehr mit Bestimmtheit dem Soorpilze selbst zuzuschreiben, und es lässt sich jetzt eine einfache ungezwungene Antwort auf die Frage geben, ,warum kommt der Soor so extrem selten im Magen vor?"6 Es hat an Erklärungen für diese etwas seltsame Erscheinung nicht gefehlt, man hat die Vermuthung ausgesprochen, dass der Pilz in seiner Vegetation an geschichtete Plattenepithelien gebunden sei, und von Cylinderzellen nicht leben könne, indessen Niemand hat in den zahllosen Hefesprossen, welche so gewöhnlich in dem Inhalte solcher Kindermagen gefunden werden, die Sprossen und Gonidien des Soorpilzes erkannt, für welchen in der sauren Magenfluissigkeit die Sprossung eben die einzig mögliche Form seiner Vermehrung ist.

Bevor ich nun auf die Stellung des Mycoderma vini als Parasiten eingehe, bleibt mir noch ein erheblicher Zweifel zu erledigen, über welchen mir nicht die zuverlässige Methode der Objectträgercultur hinweghilft, da ich ja selbst angegeben, dass ausser den Mycoderma-Zellen noch viele andere Gonidien in den Soorhäufchen vorkommen, denen gegenüber ich die Mycoderma vini als „eigentlichen Soorpilz" zu legitimiren babe. So bestimmt man auch nach längerer Uebung die Soorfädchen von anderen Pilzen unterscheiden kann, und so gewissenhaft' man sich überzeugt, dass man das, was man gesäet, auch wieder geerndtet hat, so bleibt doch zur endgültigen Entscheidung nur das Experiment übrig, der Versuch, mit den gewonnenen reinen Gonidien bei Thieren Sooreruptionen zu reproduciren. Dieser Versuch nun führt nicht ganz ohne Weiteres zum Resultat. Wie allbekannt, kommt der Soor nie bei gesunden und kräftigen Individuen, und niemals bei solchen Patienten vor, welche durch ein plötzliches, schnell tödtendes Leiden aus der Fülle ihrer Kraft dahingerafft werden, sondern bei schwächlichen Kindern und 
entkräfteten siechen Personen, zu deren langem Krankenlager er sich meist als ominöser Vorbote sub finem vitae hinzugesellt. Es darf deshalb nicht befremden, dass die Uebertragungen des Mycoderma auf die Mundschleimhaut gesunder lebensfrischer Thiere obne Ausnahme gescheitert ist. Junge Katzen nud junge ( 3 Wochen alte) Hunde wurden mit den rein cultivirten Gonidien gefüttert, sie genossen die zur Suspendirung verwendete vorber frisch aufgekochte Milch durch Wochen mit dem gleichen Appetit, ohne eine Spur von Erfolg. Nahm ich dagegen ganz junge Thiere, von 3-8 Tagen, für welche die künstliche Fütterung mit Kubmilch, so sorgfältig sie auch ausgeführt wurde, doch eine erbebliche Ernährungsstörung verursachte, so erzielte ich bei fünf Hunden, in ganz übereinstimmender Weise positive Resultate. Die 5 Thierchen gingen nach einander vom 4 . bis zum 10. Tage nach Beginn der Fütterung zu Grunde. Schon intra vitam zeigten sich auf der Zunge zahlreiche submiliare weissgelbe Heerde. Die Section ergab deren in grosser Menge in der Schleimhaut des harten Gaumens und in grösseren zusammenhängenden Einlagerungen in den Pharynxtaschen. Sie hafteten ziemlich fest an der Oberfläche, und gaben unter dem Mikroskope genau ebensolche Bilder, als die frischen Soorhäufchen der Kinder, da dichte Büschel von langen Fäden abwechselten mit solchen Stellen, an welchen vorwiegend Rundzellen (die Hefeform des Pilzes) angebäuft lagen. Eines der kleinen Thiere bot eine auffallende Sooraffection des Larynx dar. In dem rechten Stimmbande nehmlich, nahe dessen freiem Rande sass ein über Stecknadelkopf grosser gelblichbrauner Klumpen auf, nach dessen Entfernung ein flacher aber deutlicher Substanzverlust zurückblieb. Der Klumpen enthielt nichts als colossale Soorfäden, welche an dem Stimmbande eine wirkliche aphthöse Erosion hervorgebracht hatten.

Mit diesen Erfolgen halte ich den Beweis für erbracht, dass die Aussaat rein gezüchteter Mycoderma vini genügt, um bei schwächlichen, widerstandsunfähigen Thieren auf unverletzter Schleimhaut Schwämmchen hervorzurufen. Da andere Pilze, auch Mucor racemosus nie ähnliche Affectionen erzeugten, so sehe ich die Mycoderma vini für den echten Soorpilz an.

Als Parasit betrachtet, steht er der grossen Klasse derjenigen auf Pflanzen lebenden Schmarotzerpilzen parallel, welche durchaus gut auf todtem Substrat leben können, deswegen auch cultivirbar 
sind, welche aber unter gïnstigen Umständen auf lebenden und unverletzten Gewebsoberflächen sich ansiedeln, und daselbst mit einer Ueppigkeit vegetiren können, welche günstigenfalls mit dem völligen Absterben des Wirthes endet.

Favus, Herpes tonsurans, Pityriasis versicolor.

Die Literatur iiber die drei Hautmycosen ist für die verhältnissmässig kurze Zeit ihres Bekanntseins eine überaus grosse; die Hauptarbeiten finden sich indess sowohl in den Lehrbüchern der Dermatologie (J. Neuman n, Aufl. 1876) als in dem kleinen Werke von Eida m citirt, so dass ich mit den folgenden spärlichen Angaben keinen Anspruch auf Vollständigkeit erhebe, sondern nur kurz einige Vertreter der verschiedenen geltenden Ansichten nambaft machen werde. Die erste kurze Mittheilung Schönlein's 1839 (J. Müller's Arch.) sowie die diagnostischen und pathognostischen Untersuchungen Remak's (1845), welche der Beschreibung des in den Favusmassen vorkommenden Pilzes gewidmet sind, gehen von der stillschweigenden Voraussetzung aus, dass der fragliche Favuspilz ein Parasit sei, einer besonderen, anderweit noch nicht beobachteten Pflanzenspecies angehörig, welcher deswegen mit einem neuen Namen, Achorion zu belegen sei. ob der Pilz auch auf anderen Substraten gedeihe, und auf welche Weise seine Uebertragung dann auf die Haut von Menschen und Thieren statthabe, lässt Remak unentschieden, und schiebt die Lösung dieser Aufgabe den Botanikern zu.

Wie bekannt währte es einige Jahre, ebe der Parasit der Pityriasis versicolor, das Mikrosporon furfur (Malmsten 1843) und der Herpespilz, Trichophyton tonsurans (Eichstedt 1846) entdeckt wurden. Seitdem ist zu der Frage Remak's noch diejenige hinzogekommen ,sind die Parasiten dieser drei Hautkrankbeiten identisch, oder gehört einer jeden Erkrankung eine eigene, nur ihr zukömmliche Pilaspecies an?" Die directe mikroskopische Untersuchung der Hautschüppchen sowie der Favusmassen sprach für eine Verschiedenheit der Fäden und Sporen. Die Unzahl missglückter Culturversuche ergab gewöhnlich eine dichte Penicillium-, Aspergillus- oder Mucorvegetation, welche von vielen Autoren als die Hauptart angesehen ward, zu der die einzelnen Formen nur Unterabtheilungen sein sollten. Von den neueren Untersuchern, namentlich von 
Köbner ${ }^{1}$ ), Rindfleis $\operatorname{ch}^{2}$ ) und Peyritsch ${ }^{3}$ ) wurden sie dagegen als blosse Verunreinigungen erkannt und beurtheilt. Unter denjenigen Abbildungen indess, welehe von dem Favuspilze auf Grund von Culturen gegeben worden sind, finde ich - von den oben gedachten Penicillium- und Mucorresultaten abgesehen - keine einzige, welche den Lebenscyclus einer bekannten Kryptogamenart von Anfang bis zu Ende darstellte, so dass man die ausgesäten unzweifelhaften Favusgonidien z. B. durch die Keimung und Mycelbildung verfolgen könnte, bis die Sporenreifung wieder dieselben Formen hervorbringt, welche das zerzupfte Scutulum enthielt. In den Zeichnungen, welche Rindfleisch seinem Aufsatze beigiebt, und welche auf Apfelscheiben und gekochten Früchten gezüchtete Achorionstadien darstellen, lassen sich bei sorgsamem Vergleich Entwickelungsstufen erkennen, welche mindestens drei, vielleicht auch vier verschiedenen Pilzfamilien angehören. - Ebenso widersprechend als die Züchtungserfolge sind die rein klinischen Beobachtungen und die Impfungen bisher geblieben. Hebra schliesst aus seinen so reichen Erfahrungen von Uehergangsformen der einen Hautaffection in die andere auf eine Identität der Parasiten (wie er glaubt, Abarten von Penicillium); Bärensprung hält die Formendifferenzen zwischen Achorion, Trichophyton und Mikrosporon für so wichtig, dass er bei jedem solchen scheinbaren Uebergang eine frische Infection mit dem anderen Parasiten annimmt. Impfrersuche wurden niemals mit rein gezüchtetem Material angestellt, ein Vorwurf, welcher besonders diejenigen Schlüsse erschüttert, welche u. A. Pick ${ }^{4}$ ) aus Penicilliumübertragungen zieht, bei denen er sowohl das herpetische Vorstadium als den Favus selbst auf die Menschenhaut hervorgehen sah. Das einzig constante Ergebniss der Impfversucbe ist das, dass bei keiner der gelungenen Infectionen Favus direet entstand, sondern dass den Borkenbildungen stets ein herpesgleiches "Vorstadium" vorausging.

Zu den Keinculturen, welche ich nach der oben ausgeführten

1) H. Köbner, Klinische und experimentelle Mittheilungen aus der Dermatologie und Syphilidologie. Erlangen 1864.

2) Rindflelsch, Dieses Archiv Bd. LXIV.

$\left.{ }^{3}\right)$ J. Peyritsch, Beitrag zur Kenntniss des Favus. Mgrph.

4) Josef Pick, Untersuchungen über die pflanzlichen Hautparasiten. Verbandl. d. k. k. zool.-bot. Gesellsch, in Wien. Bd. XV. 1865 . 
Brefeld'schen Methode auf dem doppelten Wege der Objectträger und der Massenzuichtung anstellte, erhielt ich das sebr gut erhaltene Material zweimal aus Wien durch die Güte der Herren H. Hebra und Jarisch, einmal von Herrn Prof. Lewin; ich nehme mit Vergnügen hier Gelegenheit den Herren meinen aufrichtigen Dank für ibre bereitwillige Unterstützung auszusprechen.

Obwohl ich bei der Auseinandersetzung der. Soorculturen des höchst störenden Einflusses der mit ausgesäten Schimmelgonidien und der Schizomyceten bereits gedacht habe, so muss ich dieses Umstandes hier doch noch einmal erwähnen, da ja so viele Untersucher die erhaltenen Aspergillus-, Penicillium-, Mucor- oder Pleosporarasen als die Abkömmlinge des sogenannten Achorion wirklich angesehen und beschrieben haben. Diese Thatsache, oder vielmehr dieser Irrthum ist um so begreiflicher, wenn die Favusmassen stark eingetrocknet waren, dann in Wasser gelöst, und in die Nährflüssigkeit hineingebracht wurden. Sehr oft haben dann die längsovalen ziemlicb stark glänzenden Gonidien, welche oft genug noch mit Fadenresten zusammenbängen, und sich dadurch als Abkömmlinge des sonst protoplasmaleeren Pilzlagers erweisen, durchaus das Ansehen lebensfähiger Sporen, - allein keine Nährmasse ist mehr im Stande sie zum Keimen zu bringen und Alles, was auf solchen Culturtropfen zum Vorschein kommt, ist zufällige Verunreinigung! Die Gonidien quellen im Verlauf einiger Tage in der Flüssigkeit auf', zerfallen, und es ist dann sehr schwer zu unterseheiden, ob die zablreich vorhandenen Mycelbildungen und Keimschläuche aus den ausgesäten und lebensfrisch gebliebenen Achorionsporen, oder aus fremden Keimen hervorgewachsen sind. Bei frischeren Schildchen ist manchmal die Eintrocknung nicht so arg gewesen, dass die Keime abgestorben sind, wohl aber haben sie durch ungünstige Einflüsse an ihrer Fähigkeit, schnell zu wachsen, stark eingebüsst; sie keimen deswegen langsam aus den kleinsten Favusbröckelchen hervor, die isolirten Zellen erreichen ebenfalls nur ganz allmählich, im Verlauf von 3, 4, 5 Tagen eine Grösse von $0,1-0,5 \mathrm{Mm}$. und es ist hierbei unmöglich sie von den den Borken anhaftenden Bakterien oder den schnell vegetirenden Schimmeln zu isoliren. An eine rechtzeitige Ueberpflanzung der besten Keimlinge in einen neuen Culturtropfen ist nicht zu denken, denn die jungen Keimschläuche sind so zartwandig und so empfindlich gegen veränderte 
Diffusionsbedingungen, dass es mir nicht ein einziges Mal geglückt ist, sie mit Erfolg zu übertragen. Die Schwierigkeiten sind daher so gross, dass ich erst nach mehrmonatlichem consequenten Fehlschlagen und mit vielfachen Variationen der Nahrung das Ziel erreicht habe, eine Gonidie durch das Stadium der Mycelbildung derart zur Fructification zu bringen, dass das Ergebniss der Cultur vollkommen den verschiedenen Bildern entspricht, welche so leicht in den erweichteu Favusmassen zu sehen sind. Zuvörderst gehören hierzu ganz frische Favusmassen, oder es empfiehlt sich von aufbewahrten grösseren Stücken nur aus dem innersten geschützten Theil derselben eine kleine Probe mit der Nadel zu entnehmen. Diese Probe wird am besten direct, ohne vorherige Suspension im Wasser auf den Objectträgertropfen übertragen. Feinste Gelatine, in solcher Menge in kochendem distillirten Wasser gelöst, dass beim Erkalten eine zitternde Gallerte entsteht, ist die beste Nahrung. Sind enorm viele Bakterien in dem Favus, so ist es rathsam die Leimlösung leicht anzusäuern (Acid. lact. oder citr.). Gegen das Eindringen von Penicillium kann ich nichts Anderes empfehlen, als ein sorgfältiges Studium, über die charakteristische gablige Verzweigung der starren, meist sehr üppigen, radiär von einem Centrum sich verbreitenden Mycelien, damit man noch vor eingetretener Fructification die Häufchen mit sauberen Nadeln herausheben kann.

Das Achorion verhält sich nun wie folgt: Fig. 2 die ovalen, oder fast viereckigen Gonidien senden bei a einen, sehr gewöbnlich zwei oder (in reichlicher stark saurer Nahrung) viele Keimlinge aus. Diese anfangs ungegliederten Schläuche erhalten bald $b$ Scheidewände und senden nach Art der höheren Pilze Seitenzweige aus, welche durch Spitzenwachsthum sich verlängern. Die Gonidien liegen meist zu mehreren bei einander, hie und da scheinen sie mit einander verklebt $z u$ sein, und so kommt es, dass fast immer von einem gemeinsamen Mittelpunkte die Fäden nach allen Seiten zur Peripherie eines anfangs mikroskopischen, später grösseren Kreises vorwachsen. Es kann vorkommen, dass bereits kurze Fäden ihr Längenwachsthum einstellen, und in ganz kurze, längsovale Glieder zerfallen, $c$ deren jedes einer Achoriongonidie gleicht, und auch, wie diese auswächst. Bilder wie Fig. $2 d$ haben demnach eine grosse Aehnlichkeit mit Mycodermaketten, allein der wesentliche Unterschied zwischen beiden liegt darin, dass die Gliederhefe ihre 
Aeste und Ketten durch Knospung, der Favaspilz durch Theilung hervorgehen lässt. In der Regel werden die Fäden indess so lang, dass sie ein halbes Gesichtsfeld bei Hartnack L. V Oc. III durehmessen. Die Seitenäste, welche etwa rechtwinklig, kaum je so baumartig abgehen, als beim Pinselschimmel, und oft einen wellig geschwungenen korkzieherartigen Verlauf nehmen, sind in ihrer Anzahl äusserst varriirend. An vielen Fäden fehlen sie ganz, woraus die Meinung mancher Autoren stammen mag, dass der Favuspilz Fruchttrïger habe (Remak, Bärensprung u. A.). Die Formation des Mycels ist so mannichfach, die Verästelungen z. B. in stark saurer Lösung von Liebig'schem Fleischextract sind so zahlreich, dass sich irgend welche Paradigmen nicht wohl geben lassen. Ein Theil der Mycelfäden verläuft gleichmässig schlank bis zur Spitze, ein anderer endet mit kolbigen Anschwellungen (Fig. $2 \mathrm{e} \alpha$ ), welche den Beginn einer gabligen Theilung anzeigen. Wächst der Pilz sehr üppig, so sind Figuren wie e $\beta$ nicht so selten, wo kuglige Seitenäsțe sich abzweigen, welche gross und glänzend werden, und so durch allmähliche Abnahme ihres Slieles eine völlige Abschnürung erfahren. Solche abgeschnürten Kugeln sind wiederum keimfähig, eine Beobachtung, welche sich bei langsam wachsenden Culturen, die durchaus rein bleiben, und nicht zur Fructification neigen, sehr häufig machen lässt. Andere kuglige Auftreibungen, wie sie namentlich endständig vorkommen, oder mitten im Verlaufe eines Fadens grosse hinter einander liegende blasige Ectasien bilden, halte ich für pathologische, vom Nährsubsirat abhängige Bildungen. Die Anlage von Lufthyphen ist selten; eigentliche Fruchtträger kommen überhaupt nicbt vor. Die Bildung der Gonidien geschieht, wie mir bei den ersten gelungenen Objecten schien, vom Centrum der Fäden aus nach der Peripherie fortschreitend durch eine kurze Gliederung in anfangs fast cubiscbe Zellen, welche bald durch $\mathbf{A b}$ rundung ihrer Ränder die längsovale Gestalt annebmen, welche dem ausgesäten Achorion eigen sind. So entstehen die bekannten Bilder, wie sie erweichte Favusmassen zeigen, and wie sie Remak und auch Bärensprung abbildeñ d. h. im Centrum liegt ein unentwirrbarer Fadenknäuel und zahllose Gonidien, während theils leere, abgestorbene, theils noch protoplasmahaltige Fäden mit Quertheilung wie ein Strahlenkranz nach allen Seiten hervorstarren. Fig. $2 \mathrm{e}$ lehrt, dass diese Anschauung nicht ganz richtig ist, und ich habe 
mich ạn zahlreichen Präparaten überführt, dass die Theilung der Aeste in Gonidienketten, sowie die Bildung wirklicher Gemmen $\gamma$ (bei Erhaltung der Fadencontour) ganz unregelmässig bald central, bald peripher beginnt, dass sie bald an dem Hauptstamm anhebt, bald die kleinen Seitenästchen zuerst befällt. Jetzt erst wurde es mir verständlich, weswegen in den Zupfpräparaten sowohl, als in den von solchen entlehnten Zeichnungen so wenig in Abschnürung begriffene Fäden, namentlich Aestchen zu finden sind, da begreiflicherweise die leiseste Berührung den losen Zusammenhang der Glieder stört, und alle fruchttragenden Fäden in eine grosse Sporenmasse verwandelt, aus der nur die abgestorbenen oder noch nicht getheilten Fäden als cohärente Figuren darstellbar bleiben. Bringt man die Objectträgerculturen, welche in Gelatinelösung runde, stecknadelknopl- bis halb erbsengrosse erhabene Häufchen bilden, in Wasser, so ist weder ein Botaniker noch ein Pathologe im Stande, ein solches Präparat von frisch zerzupftem auf der Haut gewachsenen Favus zu unterscheiden. -

Herpes: Das Trichophyton tonsuranis, mit welchem ich Reinculturen gemacht, verdanke ich Herrn Departements-Thierarzt Dr. Dieckerhoff, der dasselbe einer an Herpes leidenden Kuh entnommen, sowie Herrn 0 . Simon hierselbst, welcher mir mehrere Proben von verschiedenen Patienten gütigst überlassen hat.

Selle ich diesmal von Verunreinigungen ganz ab, so zeigte der rein cultivirte Herpes der Kuh eine durchaus einförmige Gestalt sofern er in angesäuerter Gelatinelösung belassen wurde. Makroskopisch bildeten sich erhabene Häufchen, welche $1 \mathrm{Cm}$. Länge und $0,2 \mathrm{Cm}$. Breite erreichten, und aus dicht gedrängten ovalen Gonidien bestanden. Die freien Ränder gewährten Bilder wie Fig. 4a, an denen man, wie an einzelnen detachirten Gonidien, sehr leicht erkenuen kann, wie aus den kleinen stark glänzenden ovalen Zellen ein kurzer Faden entsteht, der sofort wieder in einen Zickzack von: Gonidien zerfällt, welche dann das Keimen fortsetzen. Nor hin und wieder erhielten sich einzelue längere Fadenglieder unzertheilt. -

Ein durchaus verschiedenes Bild gaben die Objecte eines anderen Falles, welche von dem Oberschenkel einer Frau stammten: Fig. 4c stellt einen Theil der zahllosen Fäden dar, welche in saurer Lösung von Fleischextract aus den Hautschüppchen herausgekeimt 
waren, und an denen besonders ziemlich zahlreiche Lufthyphen $\alpha$ mit derselben Gonidienabgliederung auffielen, wie sie der Favuspilz dargeboten. Die Fäden indess waren dünner, die Sporen kleiner, und da auch die zwischen den Epidermisschuppen massenhaft liegenden ursprünglichen Fäden nicht an Favus erinnerten, so gab ich einstweilen den Vergleich auf. Noch etwas anders als djese beiden Fälle, jedenfalls dem Trichophyton der Kuh ähnlicher, gestaltete sich das Ergebniss des dritten Falles, das Glieder von mittlerer Grösse (Fig. $3 \beta$ ) mit spärlicher Gonidientheilung, dünnem homogenen Protoplasma zeigte, und eine Menge von Vacuolen in den Zellen trug, welche trotz der Gonidienreihen den Mycelfäden ein recht dürftiges Aussehen gaben. Die Schuppen waren in äusserst diluirter stark saurer Fleischextractlösung angestellt worden. -

Pityriasis. Die Züchtungen des Pityriasisparasiten haben den Vortheil vor dem des Herpes, dass die oberflächlich liegenden Pilze derart leicht zu beobachten sind, dass man in geeigneter Näbrlösung ein Auswachsen der Fäden über die Ränder des Epidermisschüppchens und ibre Verbreitung in dem Tropfen ohne jegliche Mühe verfolgen kann. In schwach saurem dünnen Fleischextract erhält man aus den rundlichen Gonidien schwache, sparrig verzweigte, eckige, protoplasmaarme Fäden, welche in so kurze Gliederketten zerfallen, dass jede derart abgeschnürte Gonidie fast kugelrund (Fig. 3) anzusehen ist. Keimt eine solche (Fig. $3 \alpha$ ) künstlich gezüchtete Zelle in der Nährlösung wiederum aus, so pflegt sie gleich von vorn berein drej, vier oder auch noch mehrere Schösslinge auszusenden, welche mit Vorliebe in kurzen Bogenlinien verlaufen, hie und da Seitenzweige treiben, und bald auf dem nun schon mehrfach bescbriebenen Wege der Theilung vom Centrum nach der Peripherie zu ihre Gonidien abschnüren.

Wie wird sich nun nach dem eben Mitgetheilten die Frage entscheiden: Sind die drei Pilze, das Achorion Schönleinii, das Trichophyion tonsurans und Mikrosporon furfur identisch, oder ist jeder eine besondere Species? Ich für meine Person bin anfangs über die einfache Notiznahme, dass alle drei in ihrer Fructification eine genaue Uebereinstimmung zeigen, und dass diese Fructification in derselben Weise geschieht, als bei Oidium lactis, nicht hinausgekommen. Brefeld, der eines Tages die Freundlichkeit hatle, die verschiedenen Präparate, welche theils ganz rein cultivirt aufgehoben, theils noch im 
Wachsthum begriffen waren, selbst in Augenschein zu nehmen, erklärte für jedes der Objecte, dass es Formen entspreche, wie er sie unter verschiedenen Nährbedingungen an Oidium lactis beobachtet, und dass es sich vermuthlich in allen gleicherweise um Oidium lactis handle. Sei diese Muthmaassung nicht richtig, $d . h$. behielte ein jeder der Pilze durch eine grosse Anzabl ron Generationen stets seine typischen Formen, wechselte sie auch nicht in anderen Nährlösungen, so wäre eine nahe Verwandtschaft doch unzweifelhaft, und es läge der Fall vor, dass ein in der Systematologie ziemlich niedrig stehender Pilz wiederum scharf charakterisirte Einzelspecies habe, was in der Mycologie anderweit nicht bekannt sei. Auf diese Winke hin gelang es nun über Erwarten leicht durch Züchtungen, welche schnell mehrere Generationen der Pilze erzielten, bei gleicher Năhrlösung aus Favus, Herpes und Pityriasis durchaus identische Vegetationen hervorzubringen, so dass man nunmebr die gegebenen Zẹichnungen promiscue für alle drei:Parasiten gelten lassen kann. Inzwischen hatte ich für reines Oidiưm lactis (Milchcultur) gesorgt, das nun zum Vergleich angestellt wurde. Längere Zeit konnte ich mich nicht entschliessen lediglich wegen der Dickendifferenz der colossalen Gonidien der Milchcultur und der feinen Herpesfäden eine Identität für zulässig zu halten. Trotzdem bot jede neue Cultur, und auch hier worden mehre Generationen hinter einander gezüchtet, die allergrössten Varietäten; es wuchs z. B. in einem diluirten sauren Tropfen aus der grossen Oidiumgonidie (Fig. 4 b) ein so dïnnes Fädchen hervor, dass die am entgegengeseizten Ende abgesebnürte Zelle nicht den vierten Theil der Mutterzelle gross war. Um sicher zu gehen, habe ich mehrere meiner Collegen die Objecte zum Vergleich vorgelegt, - wer die manniehfachen Gestaltungen sorgfältjg angesehen hatte, war obne Bedenken überzeugt, dass nur ein einziger Pilz vorlag, und um so mehr, als es nicht schwer fiel, aus einem exquisit der Fig. 4 a entsprechenden Herpeshäufchen (Kuh) in 24 Stunden in dünnen sauren Lösungen lange Fäden darzustellen. und umgekehrt.

Bin ich nun auch bereit für die morphologische Identität der drei Parasiten unter einander und mit Oidium lactis einzustehen, so bedarf es doch noch der Prüfung ihrer physiologischen Eigenschaften: Frische Favusgonidien hatten auf meinen Arm übertragen im Verlauf von circa 14 Tagen einen markstückgrossen Herpeskreis 
hervorgebracht; es fanden sich um die kleinen Haare dieser Stelle herum in deren Scheiden sehr zahlreiche Keimschläuche; mit kurzer Gliederung (Fig. 2f), wie sie dem Oidium lactis und den Culturen sowohil des Herpes, als des Favus und Pityriasispilzes eigen sind. Wurde rein cultivirte Herpesvegetation auf eine Hautstelle verrieben, so blieb, gleichviel ob ein Verband darüber angebracht wurde oder nicht, entweder der Erfolg aus, oder die Haarfollikel dieser Stelle gingen direct in kleinste Eiterpusteln über. Impfte ich streng nach Köbner's Vorschrift mit einer Nadelspitze, welche die Gonidien wirklich zwischen die Epidermisschichten brachte, ohne natürlich Bluttropfen hervorzulocken, so trat ganz regelmässig Röthung der Stelle, kleine Bläschen, mehrfache Confluenz der Kreise, Jucken, nach 2-3 Wochen Abschilferung und Heilung ein. Diese Erscheinungen, welche einem Herpesbilde von geringer Intensität auf's Haar entsprechen, wurden erzeugt sowohl durch Impfung mit rein gezüchtetem Favus-, Herpes- und Pityriasis-Pilz als auch mit einfachem Oidium lactis! Die minimalen Nadelstiche an sich, oder Impfungen mit Penicillium waren schon am folgenden Tage nicht mehr sichtbar. Einen Favus habe ich auf meiner ziemlich dünnen und empfindlichen Haut nie produciren können, auch ist es mir nicht mit der Pityriasis gelungen; trotzdem bin ich nicht zweifelhaft, dass auf geeigneterem Boden auch diese Affectionen künstlich herstellbar sein werden. Die Erklärung, weshalb nun aus demselben Pilze nicht jedesmal dieselbe Erkrankung entsteht, darf ich wohl nach diesen Culturversuchen ungezwungen auf die günstigere oder kärglichere Nahrung beziehen, welche die Gonidien im einzelnen Falle vorfinden; es gereicht mir zur nicht geringen Genugthuang, dass die rein klinischen Beobachtungen Hebra's meinen botanischen Ermittelungen so vollgewichtig den Rücken decken. Dass Hebra für den gemeinsamen Parasiten das Penicillium angesehen, bleibt für die Hauptfrage der Identität durchaus irrelevant.

Mit den Untersuchungen des Soors, des Favus, des Herpes tonsurans und der-Pityriasis versicolor sind nun zwar njeht alle typisch verlaufenden Krankheitsprozesse erledigt, welche auf grössere kryptogamische Vegetationen bezogen worden sind, allein mein Beobachtungsmaterial ist hier am Ende, ich habe weder einen Fall von Pellagra noch von mycotischer Sycosis zu sehen Gelegenheit 
gehabt, und behalte mir vor im günstigen Falle späterhin diese Lücken auszufüllen. Von den èrörterten vier Affectionen lässt sich mit Sicherheit aussagen, dass keine derselben in dem strengsten Sinne des Wortes parasitiseber Natur ist, wie etwa die durch die Ustilago-Arten oder Exobasidium oder Peronospera infestans erzeugten Pflanzenkrankheiten, sondern dass sie durch das Wachsen von Pilzen bewirkt werden, welche auch sonst viel verbreitet auf todten Substraten vorkommen, und welche nur, durch günstige Nahrungsbedingungen einmal zum Wuchern gekommen, eine Zeit lang von thierischen Zellen leben können, und je nach ihrer Localisation und der grösseren oder geringeren Reizbarkeit des Organismus verschiedene Krankheitsbilder hervorrufen. Wie einflussreich hier gewisse individuelle Dispositionen (Dicke der Hornsehicht, Zahl, Grösse und Dicke der Haarfollikel, Schweisssecretion etc.) sind, beweist die Thatsache, dass die auf Hebra's Klinik früher gemachten Impfversuche so lange resultatlos blieben, dass an der Uebertragbarkeit des Favus überhaupt gezweifelt wurde; das Einreiben des aus Herpes gewonnenen reinen Pilzmaterials auf meinen Arm blieb ja auch oft ohne Erfolg, oder die Entzündung wurde so heftig, dass sofort eine Vereiterung des Haarbalges entstand, mit deren Verlauf die Pilzvegetation erklärlicherweise unterbrochen ward. Diese mehr äusserlichen Verschiedenheiten erklären es, dass mit dem Fortschreiten der Cultur die parasitären Hauterkrankungen immer seltener werden, sodass der eigentliche Herd für die schweren Favusformen zur Zeit in den ärmsten Bezirken von Polen and Galicien liegt; es wird so ferner begreiftich, dass eine mit Herpes tonsurans behaftete Hauskatze viel seltener Erwachsene ansteckt als Kinder, welche sich weniger energisch zu waschen pflegen, und dass auch der Herpes tonsurans fast völlig aus denjenigen Klassen der Gesellschaft verschwunden ist, bei welchen eine sorgfältigere Pflege der Haut regelmässig die Nährsubstrate für Pilzanbäufungen entfernt.

Immerhin liegt in den behandelten vier typischen Mycosen die reinste Form von pflanzlichem Parasitismus vor, welche auf Menschen oder Säugethieren überhaupt vorkommt, da die Pilze hier wirklich lebende und unverletzte Gewebe befallen und zerstören. Unberechenbar gross und in ihren Erscheinungen varjabel ist hiergegen die Klasse derjenigen Gelegenheitsschmarotzer, welche von vorn herein auf abgestorbenen, und nur noch äusserlich mit der 
lebenden Umgebung zusammenhängenden Geweben sich entwickeln. Sei es, dass ein unter den Fingernagel gerathener Splitter dem Eindringen des Myceliums den Weg eröffnet, sei es, dass lange Zeit hindurch angehäufte organische Substanzen im Gebörgange eine üppige Pilzcultur unterhalten, welche in die oberflächlich macerirten Hautschichten übergreift, sei es, dass necrotische Lungentheile den Primärsitz bilden, immer bedarf es einer verletzten 0 berfläche, eines Angriffspunktes, und immer sind wir gezwungen, diese Mycosen in Parallele zu stellen, mit den oben citirten Untersuchungen Brefeld's über die Verschimmelung schadhaft gewordener Aepfel. Wer die bahnbrechenden Beobachtungen Virchow's über diese verschiedenen Prozesse gelesen hat, wird mir beistimmen, dass sich kaum etwas Neues über diese Onycho-, Odonto- oder PneumonoMycosen sagen lässt, welche Virchow schon 1856 als blosse Secundär-Affectionen erkannt hat, welche sich kaum von dem sogenannten saprophytischen Wachsthum unterscheiden. Die casuistischen Beiträge, welche die Literatur seitdem gebracht bat, liefern den Beweis, dass eine ganze Reihe der gewöhnlichen Schimmel unter den genannten Bedingungen wuchern können, und dass eine Pneumonomycosis aspergillina sich nicht wesentlich unterscheidet von einer Lungengangrän, oder besser gesagt, Lungennecrose, in welcher eine Mucor- oder Chalaraform sich als Ansiedler niedergelassen hat. Bemerkenswerth ist ein Fall, welchen Fürbringer ${ }^{1}$ ) mittheilt, der einen an Diabetes mellitus leidenden Mann betriff, in dessen Lungen sich ausser einer Menge von Oxalsäurekrystallen mächtige Pilzlager von Aspergillus fanden, welche in der Wand der Höhlen gewachsen waren. Einen ganz analogen Fall, gleichfalls bei einem Diabetiker, habe ich kürzlich im hiesigen pathologischen Institute zu untersuchen Gelegenheit gehabt, von einem früher vorgekommenen Falle sind mir die Notizen abhanden gekommen, so dass ich nicht angeben kann, ob bei ihm gleichfalls Diabetes mellitus vorgelegen hat. Die Lungen beider Individuen enthielten in den verschiedenen Lappen verstreut liegende Herde von frischer mycotischer Bronchopneumonie (Schluckpneumonie) und daneben grössere mehr gangränös aussehende, als derart rjechende Höblen. Die frisch infiltrirten Abscbnitte sowohl, als

1) Dieses Archiv Bd. 66. S. 330 . 
die Wandungen der Höhlen waren durchsetzt von dicht verfilztem Rasen eines Pilzes, der genau übereinstimmt mit den Abbildungen Fig. f. Taf. XVIII vom Soorpilze. In den Pharynxtaschen und dem Oesophagus beider. Individuen waren enorme Soorhaufen bej den Sectionen, welche College Jürgens ausgeführt, constatirt worden. An den mikroskopischen Präparaten lässt sich unschwer ein Hineinwuchern der Pilzfäden von den kleineren Bronchien aus in die Lungenbläschen nachweisen; hie und da sieht man dichte Pilzbüschel die Wand eines Bronchus direct durehbrechen und mebr oder weniger weit in die angrenzenden, Zellen erfullten, Alveolen hineinstarren. An besonders günstigen Stellen, namentlich an grossen und zugleich hinreichend dünnen Schnitten kann man sich überzeugen, wie die um einen Bronchus gelegenen Alveolen in einem gewissen Bezirke von den Pilzen durchwachsen sind, und wie um diesen Bezirk eine periphere Zone frischer Rundzellen-Infiltration besteht, welche stets breit genug ist, um den Pilzherd vollständig von dem Gesunden abzuschliessen. Da, wo die Pilzvegetation sebr weit vorgedrungen ist, die Zone der reactiven Entzündung, bei der es auch zu Blut und Fibrinaustritt kommt, demnach sehr mächtig ist, findet man oft jene vertrockneten, dunkelrandigen, reichliche Oeltröpfehen führenden Fäden, welche die abgestorbenen Zellen charakterisiren: Ein Bild, welches ich als, den Sieg der lebenden thierischen Zellen uber die parasitisch angreifenden Kryptogamen auffasse. - Auf die Frage, weshalb nicht jeder Gangränherd der Lunge, weshalb nicht jede ulceröse Höhle eines Phthisikers, welche ja so gewöhnlich an Soor leiden, von Pilzvegetationen befallen wird, bin ich ebenso wenig im Stande, eine sichere und durchschlagende Antwort zu geben, wie jch mich bescheiden musste, bei den Mycosen der äusseren Haut auf gewisse prädisponirende Nebenumstände hinzuweisen, über welche sich einstweilen generaliter nichts feststellen lässt. Für den gegebenen Fall des Lungensoors bin jcb aus Gründen, welche in dem experimentellen Theil dieser kleinen Arbeit erörtert werden, geneigt, dem Diabetes mellitus eine hervorragende - Stelle unter diesen prädisponirenden Momenten einzuräumen. Es wird sich dort zeigen, wie mächtig eine künstlich erzeugte Zuckerkrankheit die Vegetation. gerade des Soorpilzes unter den denkbar schwierigsten Verhältnissen zu beeinflussen vermag. 
Bis hierher haben diese Untersuchungen soviel als möglich Fühlung behalten mit dem, was in dem klinischen Verlauf und dem anatomischen Verbalten bereits beobachtet worden ist. Dèr vorwiegend botanische Standpunkt, welchen dieselben inne hielten, musste nothwendig zu einer Scheidung der mỵcotischen Prozesse fübren, in einem Sinne, welcher mehr den physiologischen Ernährungsbedingungen der Pilze, als den durch sie bedingten pathologischen Vorgängen im Thierkörper Rechnung trägt, und nur darin stimmen beide Kategorien zusammen, dass diejenigen Pilze, welche unverletzte Gewebe befallen, auch typisch verlaufende Entzündungen, die Gelegenbeitsschmarotzer ganz variable Erscheinungen verursachen. Die letzten Fragen, unter welchen Bedingungen überhaupt Fadenpilze in thierischen Geweben und Säften gedeihen können, ob ihre zerstörende Wirkung eine ehemische oder mechanische ist, und welche Mittel endlich der lebende Organismus zur Tödtung und Eliminirung der fremden Eindringlinge anwendet, diese können schwerlich auf dem Wege der blossen Beobachtung einzelner Krankheitsfälle gelöst werden, sondern bedürfen einer Entscheidung durch das Experiment.

Auch hier ist es nur möglich, Fragmentarisches zu berichten, da die Anzahl der Pilzarten Legion ist, und nur eine im Verhältniss sehr geringe Menge derselben auf die Frage geprüft werden konnte: „giebt es für sie aucb an anderen Stellen im Körper als auf freien Oberflächen, giebt es in der Blutbahn oder in Geweben Näbrboden, und die Bedingungen für ihre Keimung?" - Für einige Schimmelarten und für Hefepilze sind diese Fragen schon bearbeitet worden, und ich werde bald auf die Ergebnisse zurückkommen; nachdem ich die Resultate meiner Versuche mitgetheilt, welche neben jenen in sofern einige Bedeutung beanspruchen dürfen, als sie mit einem zuverlässig reinen Material ausgeführt sind.

\section{Einführung von Sporen in's Blut.}

a) Directe Injection in eine Vene oder Arterie.

Die bezüglichen Experimente wurden an Hunden and Kaninchen ausgeführt, welchen je nach ihrer Grösse 2, 3, 5 bis $20 \mathrm{Ccm}$. destillirtes Wasser, 1procentige Kochsalzlösung, verschiedene Nährlösungen in die Carotis, Vena jugul. oder Vena femoralis injicirt wurden, nachdem vorher die Pilzsporen in den Flüssigkeiten suspendirt 
waren. Zur Verwendung kamen Penicillium glaucum, Eurotium Aspergillus glaucus, Eurotium Asp. niger., Mucor mucedo, Mucor stolonifer, Mucor racemosus, Oidium lactis, das sogenannte Oidium albican's, Hefe, und ein Insecten tödtender Pilz, die Muscardine. Die Anzahl der Injectionen beträgt insgesammt über 200, und das Ergebniss war ein constant negatives. Sofern man nur ganz reines Material verwendet, und die Menge der Flüssigkeit nicht allzn hoch greift, ist die Einbringung auch noch so vieler Sporen der genannten Arten ein durchaus indifferenter Eingriff! Die sehr häufig beobachteten Erscheinungen des Erbrechens, der wässerigen Stühle etc., welche Pop of ${ }^{1}$ ) von der Anwesenheit der Pflanzenzellen, namentlich der Hefe herleitet, stehen in ihrer Intensität in geradem Verhältniss zu der Quantität der Flüssigkeit, welche in die Blutbahn eingeleitet wurde, und andere Beobachtungen, namentlich in Ponfick's Experimentalarbeit über Transfusion thun mit Gewissheit dar, dass ein Causalnexus in Pop off's Sinne durchaus nicht existirt. Wenn ich absichtlich Schizomycetenkeime mit oder ohne faulige Flüssigkeiten der Injectionsmasse zusetzte, so entstand eine septische Intoxication, welche in mehr oder weniger foudroyanter Wirkung den Tod herbeiführte; wenn ich einem Hunde übergrosse Mengen $30 \mathrm{Ccm}$. Bierwürze mit den darin enthaltenen Hefezellen einspritzte, so entstanden Nierenhämorrhagien - von den einfachen Sporeninjectionen hat keines meiner Versuchstbiere einen directen Schaden davongetragen.

Ganz von selbst ergiebt sich hieraus die Frage: „Was wird aus den Sporen inverhalb der Blutbahn?" und sie soll gleich hier erledigt werden, da auch bej den Injectionen in seröse Höhlen etc. ähnliche Vorgänge stattfinden, als bei der directen Transfusion der Sporen in's Blut. 1) Ein Theil derselben geht in der umgebenden warmen und stetig circulirenden Blutflüssigkeit zu Grunde. - Gleich nach der Operation, bis 24 Stunden später finden sich in Blutproben, wenn die Menge der Sporen sebr reichlich war, in jedem Tropfen mehrere runde, ; oft nicht leicht als Pflanzenzellen erkennbare hell transparente Körperchen, welche mit Jodlösung gelb bis gelbraun, mit Jod und Sehwefelsäure dunkelbraun bis schwarz sich färben. $O$ ft sind 2 kleine derartige Kügelchen noch

) Leo Popoff, Untersuchungen über die Wirkung der Bierhefe und der in der Pasteur'schen Flüssigkeit enthaltenen Organismén auf den thierischen Körper. Berl, klin. Wochenschr. 1872. No. 43. 'S. 513. 
mit einander verbunden, wie die jungen Knospen mit den Hefezellen, zuweilen lassen sie mit Leichtigkeit die meist excentrisch glänzenden Fettkörnchen erkennen, welche der unveränderten Hefe und auch andere Gonidien eigenthümlich sind. Ich habe Formen gefunden, welche deutlich Fragmente einer grösseren ovalen Zelle darsteliten, aus deren Peripherie ein mehr oder weniger grosses Stück ausgebrochen war. Die grösseren transparenten weichen Kugeln nehme ich nicht Anstand, für gequollene und der Auflösung nahe Gonidien anzusehen, die kleineren halte ich für zerbröckelte, oder besser gesagt durch die mechanische Gewalt des Blutstroms zerschellte Formen.

Gegenüber der von Pflanzenzellen sonst bekannten Resistenz gegen verdünnte Alkalien, sowie selbst gegen die Procedur des Kochens erscheint die Deutung, dass die Sporen in der schwach alkalischen und höchstens $40^{\circ} \mathrm{C}$. warmen Blutflüssigkeit geradezu aufgelöst wurden, auf den ersten Blick etwas gewagt. Allein die Richtigkeit der Beobachtung lässt sich auch ausserhalb des'Thierkörpers in einem Glasgefässchen leicht bestätigen. Sät man massenweise Penicillium-Sporen in schwach alkalisches künstliches Serum aus, das an sich kein sehr geeignetes Nährsubstrat für diesen Pilz ist, und stört obenein durch häufiges oder gar constantes Umrühren der Flüssigkeit die Kejmung, so findet man schon nach 24 Stunden (bei gewöhnlicher Zimmertemperatur) und je länger die Zeit, um so zablreicher, runde, stark aufgequollene Formen, welche jenen vollkommen gleichen, welche das Thierblut einige Zeit nach der Injection aufweist. Diese Anfangs noch kugligen Gebilde zerfliessen dann zu einer formlosen glasigen Masse - sie erleiden eine wirkliche Auflösung. Selbstredend entzieht sich dieser Vorgang der directen Beobachtung, wenn die Zellen der Circulation einverleibt waren, indessen lässt sich aus den erwähnten Quellungserscheinungen wohl mit Gewissheit ein gleiches Schicksal derselben erschliessen.

2) Des anderen Theiles der Sporen, welche nicht so schnell aufgelöst werden, entledigt sich der Thierorganismus mittelst Ausscheidung durch die Nieren. Es findet hierbei nicht eine Ruptur der Nierencapillaren, elwa der Glomerulusschlingen statt, wobei mit dem austretenden Blute gleichzeitig die Sporen in die Harnwege gelangten, sondern ohne das Vorhandensein von Blutkörperchen im Harn, ohne dass nach 
dem Tödten der Thiere Hämorrhagien in dem Nierengewebe nachgewiesen werden konnten, enthielt der Harn der Versuchsthiere oft recht zahlreiche runde Pilzzellen. Einige Hunde hatten sich gewöbnt, den Harn freiwillig in ein vorher auf das sorgfältigste gereinigtes und geglühtes Glasschälchen zu entleeren; andere wurden mit einem gleichfalls sorgsam gereinigten Katheter in kürzeren Zwischenräumen katheterisirt, und in beiden Reihen von Fällen fanden sich in den ersten 24 Stunden nach der Sporeninjection ausnahmslos, von da ab bis 48 Stunden spärlicher, und später nur ganz vereinzelt Pilzelemente im Harn vor. Meist waren es die kleinsten Formen, welche die halbe Grösse eines rothen Blutkörperchens kaum überschritten; zuweilen waren zwei scharf contourirte glänzende und bei einer gewissen Einstellung lichtroth, bei einer anderen grünlich schimmernde Knöspchen noch mit einander verbunden, die grösseren waren gequollen, und auch in dem Harn kamen Formen mit defecten abgebröckelten Rändern zu Gesichte, wie deren oben bei der Untersuchung der Blutproben bereits gedacht wurde. In grosser Zabl waren die Gonidien auch in dem Harn von Kaninchen suspendirt, welcher unter allen Cautelen aus der Blase des frisch getödteten Thieres auf den objectträger gebracht wurde. Die Färbung mil Jod, die Resistenz gegen Essigsäure und Kalilauge, die bei vielen Formen beobachteten excentrischen Fettkörnchen oder centralen Vacuolen liessen keinen Zweifel an der pflanzlichen Natur der fraglichen. Kugeln. Ueber die Art der Ausscheidung, d. h. über den Weg, welchen die Zellen einscblagen, um ohne eine Continuitătstrennung die Capillarwände zu passiren, babe ich an den mikroskopischen Präparaten keinen Aufschluss bekommen. Eine Anhâufung in einzelnen Glomerulusschlingen habe ich nie gesehen, ich lasse indessen diese Frage auf sich beruhen, da sie für das vorliegende Thema zu weit fübren würde.

b. Indirecte Einführung der Sporen in die Blutbahn.

Diese Ueberschrift präsumirt gewissermaassen die Resultate, welche bei einer Einbringung der Pilzsporen in die grossen serösen Säcke der Pleura und namentlieh des Peritoneums gewonnen wurden, da ihr Effect der Einfuhrung in das Blut fast gleichzusetzen ist. Wasser mit oder obne Kochsalz, in welchem die Sporen jedweder oben aufgeführten Pilzgattung suspendirt sind, wird in ganz kurzer Frist mit denselben resorbirt, wenn es auch bis zur voll- 
kommen graugrünlichen Trübung mit ihnen versetzt worden ist. Wenn man ein Kaninchen $\frac{1}{4}$ Stunde nach einer solchen Injection, welche etwa $6-10 \mathrm{Ccm}$. Flüssigkeit betrug, tödtet, so findet man meist gar keine freie Flüssigkeit in der Bauchhöhle vor. Die ausgebreiteten Lymphgefässnetze des Zwerchfells sind erweitert und vollgepfropft mit den runden oder ovalen Pflanzenzellen, welche namentlich dann sehr leicht erkennbar sind, wenn man sie vorher durch Kochen in Alizarinlösung gefärbt hat. Wenngleich diese Methode des Kochens sich nicht bewährt für die Auffindung von Sporen, welche mehrere Tage zuvor eingespritzt waren, so ist es docb leichter neben ibnen die mit eingebrachten ungefärbten, lebenden und gequollenen Zellenformen kurze Zeit darauf als solche zu erkennen, und von thierischen Zellen oder deren Kernen zu unterscheiden. Weniger zahlreich findet man ferner die Pilzelemente in den Lymphbahnen der Mesenterien und des Parietalblattes des Peritoneum, sie alle sind schon auf der Wanderung in die Blutbahn begriffen. Lässt man das Kaninchen länger, etwa 24 bis 36 Stunden leben, so weist die Section weder freie Flüssigkeit, noch freie Sporen in cavo abdominis mehr nach. Die Lymphgefässe entbalten nur spärliche, zuweilen grössere und ebendeswegen eingekeilte. Zellformen, welche hin und wieder eine mikroskopisch bemerkbare Rundzellenanhäufung hervorrufen, dagegen gelingt es leicht, dieselben kleinen Gonidien im Harn aufzufiuden, welche derselbe bei directer Injection in die Blutbahn hatte erkennen lassen. Eine Keimung habe ich unter den obigen Bedingungen bei keiner der angewandten Pílzarten je gesehen, und auch an diesen Operationen ist mir keines der Versuchsthiere direct erkrankt, oder zu Grunde gegangen. - Ganz analog der Peritonealböhle verhielt sich das Cavum pleurae (Versuche an Hunden) und die vordere Augenkammer. Die Injectionen in die letztere Höhle wurden mit einer scbarfen, womöglich neuen oder frisch geschliffenen Canüle einer Pravaz'schen Spritze so ausgeführt, dass zuvörderst aus dem Stichkanal langsam das Kammerwasser entleert, und dann einige Tropfen der Sporenflüssigkeit eingespritzt wurden. War die Suspension eine sehr concentrirte, so sah man durch die Hornhaut den eintretenden Tropfen sich gleich einer grauen Nebelwolke in dem Kammerraum vertheilen; sein Abfluss nach, aussen wurde durch die schräg angelegte. Hornhautwunde, deren Ränder sich unmittelbar 
hinter der entfernten Canüle schlossen, sicher verhindert, Schon am nächsten Tage war Alles resorbirt, und ich habe mebrfach die Injectionen an demselben Auge wiederholt ohne eine Spur von Wachsthum oder eine nachtheilige Wirkung für das Thier zu erzeugen, selbst wenn ich die Sporen in einer für ihr Gedeihen günstigen Suspensionsflüssigkeit eingebracht hatte.

Einführung von Sporen in thierische Gewebe.

a. Subcutanes Fettgewebe: Lassen sich die Schicksale, welchen die Pflanzenzellen bei den bisher besprochenen Injectionsweisen unterworfen sind, lässt sich vor Allem der Vorgang der Resorption bei der Bauch- und Brusthöhle wegen der Massenhaftigkeit der verwendeten Pilzzellen, in der vorderen Augenkammer wegen der Möglichkeit einer directen Beobachtung relativ leicht verfolgen, so begegnet man mannichfachen Schwierigkeiten bei der hypodermatischen Application. Einmal erzielt man auf diese Weise bei Kaninchen mit grosser Regelmässigkeit Abscesse, wenn man sich nicht auf ganz minimale Mengen beschränkt, zum Anderen ist selbst bei Hunden die Resorption nie eine so totale, dass man nicht nach einigen Tagen in dem leicht ödematösen, oft durch kleine Hämorrhagien rothbraun gefäpbten Gewebe der Injectionsstelle, noch wohl erhaltene Pilzsporen vorfände. Auch bei Hunden erregen die Pilzzellen im Unterhautfétgewebe gelegentlich Eiterung, zumal wenn ibre Anzahl sehr erheblich ist, und ausserdem hat hier noch ein anderer Vorgang statt, welcher eine Aufnabme der Zellen in die Lymphresp. Blutbahn geradezu unmöglich macht. Nicht ganz selten beobachtet man nehmlich bei der mikroskopischen Musterung des subcutanen Gewebes, dass in der Nähe der Injection ein ganzer Haufe zusammengeballter Gonidien ron jungen Spindelzellen rings umgeben und umschlossen liegt, welcher bier von dem Granulationsgewebe einfach abgekapselt wird. Dennoch giebt es einen Versuch, weleber die Mutbmaassung, dass auch vom subcutanen Gewebe aus die corpusculären Elemente resorbirt werden, über allen Zweifel erhebt, und gleichzeitig in das feinere Geschehen dieses Vorganges einen wichtigen Einblick gestattet.

Injicirt man einem Hunde an einer Stelle des Körpers, etwa über der linken Scapula subcutan eine grössere Menge von Schimmelsporen, und erregt gleichzeitig an einer beliebigen anderen Stelle, etwa uber der 
rechten Scapula durch Injection einer reizenden Flüssigkeit mit einer anderen (vollkommen reinen) Spritze eine Eiterung im Unterhautfettgewebe, so findet man eine grosse Anzahl von Eiterkörperchen in diesem Abscess, welche 1, 2, 3, ja 4 und 6 Sporen in ihrem.Protoplasma beherbergen. Dieselbe Er'scheinung erbält man, wenn der Abscess bei einem Thiere erzengt wird, welchem die Pilzkeime direct in das Blut oder in die Bauchhöhle eingeführt waren. Um mich auch hier vor einer Täuschung zu schützen, wandte ich ausser den ublichen Reaclionen mit Essigsäure und 1procentiger Kalilauge in Anilinroth gefärbte Sporen an, welche zwar sehr abblassten, aber doch vielfach einen so deutlichen rosa Schein behielten, dass die qu. Präparate für Andere leicht demonstrabel wurden. Obgleich ich bei mehreren Versuchsthieren, welchen an den Extremitäten Sporen unter die Haut eingespritzt waren, die nächst central gelegenen Lymphdrüsen untersucht habe, ohne in ihnen Pilzzellen zu finden, so unterlasse ich doch an dieser Stelle eine weitere Erörterung des hier Platz greifenden Resorptionsvorganges, da eine solche den Rahmen dieser Arbeit weit überschreiten würde. Gleichviel also, ob die kleinen runden Gonidien die Lymphdrüsenkette passirt haben, ob sie von den contractilen Zellen anfänglich in die Blutbahn hineingeschleppt oder durch den Säftestrom dorthinein gelangt sind, - Thatsache ist, dass sie in den Eiterkörperchen des Abscesses eingeschlossen sind, und dass sie auf dem weiten Wege, den sie zurückgelegt, nirgends Wachsthumsansätze gemacht haben. Man könnte annehmen, dass sie ihre Keimfähigkeit eingebüsst hätten, allein ich sah solchen Abscesseiter, den ich in ein durchaus sauberes Schälchen hatte einfliessen lassen, am nächsten Tage so voller junger Keimlinge von Penicillium gl., dass ich nicht glaube, dass diese alle während des Auffangens aus der Luft hineingefallen sein sollten. Zur Sicherstellung diẹser. Frage habe ich vielfach aus dem Blute der Versuchsthiere am. ersten, zweiten und dritten Tage nach der Sporeninjection mittelst zugeschmolzener Capillarröhrchen, welche in einer Vene abgebrochen wurden, Proben entnommen, und diese, nachdem das unterste Ende des Röhrchens wiederum zugesehmolzen war, durch die achtfache Fliesspapierkappe gestossen, welche einen Kolben mit frisch gekochtem Pflaumendecoct verschloss, und in dieses einen Theil des Blutes entleert. Obgleich ich bei diesem Verfahren bald negative, bald entschieden positive Erfolge erzielte, so lege ich 
auf die letzteren doch nur wenig Werth, da eine absolute Sicherbeit trolz aller raffinirter Vorsicht nicht zn erreichen ist, und da die Keimfähigkeit der. Zellen aus anderen, später anzưführenden Experimenten genugsam hervorgeht.

b. Muskelgewebe, das ich nur kurz besprechen will, eignet sich durcbaus nicht für die Lösung der interessirenden Frage nach den Schicksalen der eingebrachten Pilzsporen, da seine Irritabilität so gross ist, dass bei Hunden, geschweige deun bei Kaninchen ohne Ausnahme eine Eiterung auf die Injection folgt, welche jede reine Untersuchung unmöglich macht.

c. Das Knochenmark würde ohne Zweifel ein ähnliches Misslingeu ergeben baben, wenn ich seinem Gewebe durch Anbohren der Knochensubstanz sporenhaltige Lösungen einverleibt hätte. Ich schlug deswegen einen Umweg ein, indem ich einem Hunde eine grosse Menge von Penieilliumgonidien in die Vena jugularis einführte, und gleich darauf eine Fractura cruris machte. Acht Tage nach dem Eingriff wurde das Thier getödtet, und die Bruchstelle untersucht. Eine erbebliche Hämorrhagie erstreckte sich zwischen den Muskeln und im Gewebe der letzteren selbst in einige Entfernung von den Knochenenden hin, das Periost war geschwollen, die umgebenden Weichtheile derb und serös infiltrirt, das Knochenmark von frisch rotber Farbe. Mikroskopisch fanden sich an allen genannten Stellen, auch im Knochenmark, anscheinend durchaus normale, nicht einmal stark gequollene Penicilliumgonidien, welche hie und da zu ganzen Klümpchen vereint Jagen, ohne die geringsten Spuren eines eigenen Wachsthums noch in einer Reizung der urngebenden thierischen Gewebe zu verrathen. Unstreitig würden sie in den Callus mit eingekapselt worden sein, und hätten sich hier ebenso reactionslos verhalten, wie in dem analogen Fall des Unterhautfettgewebes.

Einstweilen mag mit dieser Reihe von Versuchen ein Abschluss gemacht werden, da die Zahl der Einzelfälle gross genug ist, um aus ihr das Facit zu ziehen, dass die Sporen aller auf Seite $\mathbf{5 7 3}$ namhaft gemachten Pilze in die Blutbahn gebracht, zum Theil aufgelöst, zum Theil durch die Nieren ausgeschieden. werden; dass sie innerbalb der Gewebe 1. der Resorption anlieimfallen, 2. durch Eiterung eliminirt werden oder 3. als unschädliche Fremdkörper eingekapselt werden können. Niemals findet unter den geschilderten 
ganz normalen Verhältnissen und bei Anwendung der genannten Schimmelarten eine Keimung der Gonidien im Blut oder in den Geweben statt.

Fragen wir nach dem ,warum nicht?" so bin ich zwar nicht in der Lage für eine erschöpfende Antwort garantiren zu können, indessen sind es wesentlich vier Punkte, welche nach meiner Ueber-. zeugung als Hemmnisse des Wachsthums in Betracht kommen müssen.

1. Die Alkalescenz des Blutes und der Gewebe. Ich bin entfernt zu behaupten, dass die genannten Pilze eines sauer reagirenden Nährbodens als absoluter Lebensbedingung bedürften. Oidium lactis, der Soorpilz und sogar das weit höher organisirte Penicillium gedeiht im Nothfalle auf alkalischem Harn, indessen bedarf es keiner grossen Erfahrung in der Mycologie um zu constatiren, dass Fadenpilze nicht nur ungleich üppiger, sondern aucl ungleich schneller auf saurem Substrat gedeihen und wuchern. Ein einfacher Vergleich giebt bierfür einen sicheren Beweis: Wenn man in einem Schälcben künstliches oder natürliches (alk.) Serum mit Penicillium oder gar Aspergillussporen zur Keimung anstellt, so dauert es selten weniger als 24, meist über 36 Stunden, ehe man ein Wachsthum wahrnimmt, während in einem Controlschälchen, dessen Serum durch eine organische Säure leicht angesäuert ist, binnen 12-18 Stunden weitverzweigte Mycelien gebildet sind. Ist es sonach sicher, dass die Alkalescenz allein, ganz abgesehen von der sonstigen chemischen Zusammensetzung der Nahrung, keine kräftige Vegetation der fraglichen Schimmelpilze zulässt, so ist auch die blosse Verzögerung in dem Auskeimen, wie sie durch die vorstehenden Zahlen : dargestellt wird, wichtig genug, da die Zeit von 36 stunden fast den äussersten Termin kennzeichnet, bis zu- welchem noch lebensfähige, d. h. nicht gequollene Gonidien im Blute nachgewiesen werden können.

2. Die Bewegung. Den Einfluss der Bewegung auf das Wachsthum der Fadenpilze habe ich an einem kleinen Apparat studirt, welcher durch ein Schaufelwerk von Blechplätteben eine Nährflüssigkeit tagelang in langsam rotirender Bewegung erhielt. Die Nährflửssigkeit bildete in allen Fällen künstliches Serum, das frisch bereitet, entweder unvermischt oder mit einigen Tropfen Acid. acetic. angesäuert verwendet wurde. In diese Näbrlösung wurden ausge- 
săt Gonidien von Penjeillium, von Mureor mucedo, von Oidium lactis und dem Soorpilz. Es liegt in der Natur der Nährlösung, welche nicht gekocht werden konnte, ohne dass ihr Eiweiss zur Gerinnung gebracht worden wäre, ferner in dem Rotationsapparat, dessen Deckel für die Welle des Schaufelwerkes eine Oefinung hatte, dass ein Abschluss für andere Pilzkeime nicht zu erreichen war. Demnach erfolgte jedesmal, und zwar je stärker und häufiger die Umdrehungen, um so reichlicher eine Entwickelung von Schizomyceten. Gerade an denjenigen Stellen, an welchen der Strom am stärksten, die Reibung am grössten war, d. h. an den freien Rändern der Schaufelchen und an den Bohrlöchern derselben ging die Entwickelung von Mikrococcen und Bakterien am rapidesten vor sich. Trotzdem blieb eine Keimung der Fadenpilze nicht ganz aus. Sowohl Oid. lactis, als der Soorpilz zeigten häufig, zumal in leicht säuerlichem Serum Sprossungen, welche 1, 2, 3 Tage lang zu Fäden weiter wuchsen, und erst dann durch die Kabmpilze überwuchert, zu Grunde gingen. Dass indessen in der dauernden Bewegung ein sehr erschwerendes Moment für ihre Entwickelung gesetzt wurde, beweisen die Controlversuche, welche constant trotz der üblen und störenden Mitwirkung der Schizomyceten ungleich reichlichere - und ungleich kräftigere Mycelien aufwiesen. Die Gonidien von Mucor und Penicillium babe ich nie in der bewegten Flüssigkeit keimen sehen, sie zeigten stets die schon öfters erwähnten Quellungserscheinungen, flossen gewöhnlich zu grösseren glasigen Klümpchen zusammen und wurden durch das blosse Auflegen eines Deckgläschens auf das Object bis zur völligen Unkenntlichkeit zerquetscht. Ein Apparat, weleher die Flüssigkèit in stürmischer wirbelnder Bewegung erhalten hätte, stand mir nicht zur Verfügung, indessen habe ich häufig Nährtropfen (Fleischsaft, Muskelinfus) untersucht, welche Wegner zu anderen Zwecken in einem offenen Gefässchen wochenlang einem solchen starken Strudel unterwarf, obne dass ich je einen Keimling irgend eines Hyphomyceten darin entdeckt hätte.

3. Der Mangel an freiem Sauerstoff muss a priori als ein Wachsthumshemmniss für die fraglichen Pflanzen-Organismen, angesehen werden, welche, wie namentlich Brefeld's exacte Versuche ${ }^{1}$ ) 
beweisen, eines gewissen, freilich sehr geringen Quantums von 0 nicht entrathen können. Die groben Experimente, welche sich auf ein Aussäen von Pilzsporen auf den Boden eines mit Nährlösung gefüllten, verscblossenen Gefässes beschränken, ergehen bereits für einige Schimmelarten recht beträchtliche und leicht nachweisbare Differenzen im Wachsthum. Aspergillus-Gonidien z. B. keimen unter 0-Abschluss sehr kümmerlich und gehen stets bald völlig aus. Eine Fruchtbildung, sofern sie auf besonderen Fruchtträgern stattfindet, wie die Pinselbildung bei Penicillium, die basidientragenden Köpfchen von Aspergillus, die Sporangien der Mucorineen, alle diese höheren Vegetationsstufen sind direct gebunden an die Anwesenheit von freiem Sauerstoff. Der Einfluss des Sauerstoffmangels auf die Mycelbildung ist wobl am frappantesten bei Mucor racemosus, welcher in gährungsfähigen Nährlösungen statt zu den bekannten eingliedrigen Hyphen auszuwachsen, dichtgedrängte Gemmen abschnürt, und geradezu alkobolische Gährung erregt.

Die Beispiele, welche ein reges 0-Bedürfniss der Fadenpilze darthun, könnten leicht vermehrt werden, es könnte wohl gar für eine Reihe von Fadenpilzen bewiesen werden, dass aus dem.Mangel dieses Factors allein ihr Gedeihen innerhalb der Blutbahn eines Warmblüters unmöglich sei, doch mag das Angeführte genügen, um die Richtigkeit meiner Behauptung zu bestâtigen, dass das Feblen des freien Sauerstoffs wenn nicht hindernd, so doch erschwerend auf die Keimung der Pilzgonidien einwirkt. Dass gewisse niedere Pilzarten mit $\mathrm{dem}$ Minimum von 0 auskommen können, welches die Gewebe und deren Säfte enthalten, wird später gezejgt werden; sehr unwahrscheinlich ist es, dáss es auch die höheren Familien vermögen.

Wie aus der Besprechung der drei voraufgeschickten Punkte erhellt, ist keiner derselben für sich so schwerwiegend, dass er allein ein absolutes Hinderniss für das Auskeimen von Pilzsporen (der sämmtlichen anfangs genannten Arten) abgeben köunte. Durchaus fern liegt es mir z. B. für die niedriger organisirten Gattungen des Didium die Möglichkeit ihres Wachsthums in schwach alkalischen bewegten und dabei der freien Luft exponirten Flüssigkeiten für eine Ausnahme zu halten; ich gebe auch zu, dass Fadenpilze existiren mögen, welche gegen das Zusammenwirken aller drei Factoren widerstandsfähig sind, ich behaupte nur, dass jeder einzelne Um- 
stand sich als störend für die Keimung herausstellt, und dass jeh keinen Pilz kenne, welcher der deletären Einwirkung aller drei vereint Trotz bieten könnte. Welcher Factor in jedem concreten Falle die Hauptschuld trägt, wird sich durch Culturversuche unschwer ergeben, da jeder derselben einer Controle durch das Experiment zugänglich ist, und ein jeder. Pilz auf sein Verhalten gegen alkalische Nabrung, gegen Bewegung und auf sein Bedürfniss nach 0 geprüt werden kann. Als ferneren Momentes bätte ich der thermischen und chemischen Einflüsse erwähnen sollen, welchen die Sporen in thierischen Geweben ausgesetzt sind, allein nach zahlreichen Experimenten liegt der höchste Wärmegrad, unter welchem Pilzsporen noch keimfäbig sind, beträchtlich $\left[16^{\circ} \mathrm{C}\right.$. für Penicillium $\left.\left.{ }^{1}\right)\right]$ uber der Bluttemperatur, so dass dieser Einwand bedeutungslos wird; die chemische Beschaffenheit des Nährbodens dagegen soll, soweit darüber Schlüsse möglich sind, unter dem 4. Gesichtspunkte und am Schlusse der Arbeit abgehandelt werden.

4. Die Anwesenheit lebender thierischer Zellen.

Während es leicht war, den Einfluss der drei voraufgeschickten Punkte durcb Versuche zu controliren, welche ausserhalb des Thierkörpers mit Nährflüssigkeiten von bekannter Zusammenselzung angestellt und auf dem Objectträger einer unausgesetzten Beobachtung zugänglich gemacht werden konnten, so haben wir nur eine entfernte Analogie, welche die Wechselwirkung der beiden Zellenarten, der thierischen und pflanzlichen, ausserhalb des Körpers zu veranschaulichen geeignet ist. Diese Analogie liegt in dem so oft zu beobachtenden Streit um das Dasein, welchen die cultivirten Fadenpilze gegen die schnell wuchernden Sebizomyceten zu bestehen haben. Werden beide Arten gleichzeitig auf ein flüssiges Nährsubstrat ausgesät, das für beide annähernd gleich günstige Bedingungen der Ernährung bietet, so verkümmert der höhere Pilz schon von dem ersten Aussenden seiner Keimscbläuche an. Selbst wenn er mit der erstaunlichen Geschwindigkeit des Penicillium gl. wächst,

1) Die Angạben über die Wärmegrenzen, innerhalb deren die gewöhnlichen Schimmelpilze ihre Kejmkraft erbalten können, sind sehr schwankend; Sporen von Penicillium glaucum verlieren in geeigneter Näbrflüssigkeit auf $55^{\circ} \mathrm{C}$. erwärmt, ihr Keimvermögen vollståndig. Sie sollen nach Wiesner nicht unter 1,5 und nicht über $43^{\circ} \mathrm{C}$. keimen; ihr Temperaturoptimum liegt bei $22-26^{\circ} \mathrm{C}$. 
gelingt es ibm nicht der Bakterien Herr zu werden, er stirbt friber oder später $a b$, und ist dann nur noch mit Mühe in den dichten Zoogloeahaufen kenntlich. Ganz beiläufig sei bemerkt, dass die Schizomyceten gelegentlich in die Hyphen der höheren Pilze selbst eindringen, diese durch ihr Wachsthum auf das Vjerfache ihrer normalen Dicke ausdehnen, und so ampulläre Anschwellungen erzeugen, welche für die in kleinen Arterien, bes. den Glomerulusschlingen, vorkommenden Mikrococcenembolien als Paradigma dienen können. Sät man die Sporen von Fadenpilzen rein aus, und siebt dieselben kräftige Mycelien treiben, so ist der Einfluss um so bemerkenswerther, welchen einige nachträglich in die Nährflüssigkeit gebrachte Schizomyceten auf die fernere Entwickelung der erstereu ausüben. Es währt nehmlich nicht lange, so hat dieses mikroskopische Unkraut den ganzen Culturtropfen überwuchert, und die Hyphen des höheren Pilzes gehen in der Mehrzahl der Fälle unter, noch ehe mit der Fruchtbildung der natürliche Abschluss ihrer Vegetation erreicht ist. Diese Uebermacht der ganz niederen Species ist nun nicht einfach in einer durch sie bewirkten chemischen Decomposition des Näbrsubstrates zu suchen, denn dasselbe bleibt noch eine gute Nahrung für höhere Pilze, wenn man durch Kochen die Vermehrung der Schizomyceten unterbricht; es bleibt vielmehr nur übrig anzunehmen, dass die kleinsten Organismen, welche die Fäden dicht umlagern, ein so überwiegend regeres Assimilationsvermögen besitzen, dass sie den concurrirenden grösseren Pilzen die vorhandene Nahrung vorwegnehmen, und sie geradeswegs durch Aushungern tôdten.

Wie betont gilt diese Beobacbtung indessen nur für flüssige Nährsubstanzen, welche bei der besten chemischen Composition doch nicht der echte Boden für höhere Fadenpilze sind, da diese hier von denselben Bakterien vernichtet werden, welche ihnen auf festem Substrat eine durchaus wirkungslose obnmåchtige Concurrenz bereiten würden. Ueberträgt man diese Erfahrung auf die Thierversuche, so erscheint es weder befremdend noch sehr gesucht, wenn man den lebenden thierischen Zellen, welche hier offenbar in dem fựr sie geeignetsten Nährbóden von den fremden Zellen angegriffen werden, eine ähnliche Rolle zuschreibt, wie sie in den Culturversuchen von den Bakterien' gespielt wird. Der blosse Mangel freien Sauerstoffes und eines sauren Nährmaterials macht es mir nicht 
erklärlich, dass auch bei sehr anspruchsloser Pilzen, wie dem Soorpilz, keine Keimung stattfindet, wenn mehrere Cubiccentimeter sporenhaltiger Flüssigkeit einem Hunde subcutan injicirt werden. Die Keimung bleibt sogar aus, wenn gleichzeitig durch Lufteinblasen ein künstliches Emphysem der betreffenden Hautstelle hervorgebracht wird, und ich stelle mir deswegen vor, dass die dort vorhandene Nahrung gerade ausreicht, die Gewebszellen zu versorgen, ohne dass für die fremden Eindringlinge irgend etwas von Nährgehalt abfällt. Sucht man die absolute Menge des letzteren zu erhöhen dadurch, dass man durch Compression einer grossen Vene ein küustliches Oedem schafft, so wird auch hier für die Sporen nichts gewonnen, da sie unter diesen Verhältnissen zwar stark quellen aber hierdurch einen solchen Reiz auf die umliegenden Gewebe ausüben, dass diese solort mit einer Zellenproduction ihrerseits, mit einer Eiterung antworten. Auch für den citirten Fall, in welchem die Sporen 8 Tage vach dem Knochenbruche ganz unversehrt aufgefunden wurden, erscheint mir der Sauerstoffmangel nicht ausreichend, um selbst das erste Austreiben der Keimlinge zu verhindern, das doch so tausendfach unter Wasser, am Boden von flüssigen Nährmitteln beobachtet wird, und auf Kosten - weniger der Umgebung - als eines in der Spore selbst enthaltenen Reservenahrungsstoffes stattindet. Die energische Gewebsthätigkeit, welche hier die Menge von Zellen producirt, welche die Callusbildung und den Heilungsvorgang einleiten, sie ist meiner Auffassung nach der eigentliche die Pilzentwickelung binderude Factor.

Der Einfluss der rothen uud farblosen Blutkörperchen wird freilich sehr verdunkeit durch die gleichzeitige deletäre Wirkung der durchaus flüssigen Intercellularsubstanz, der alkalischeo Reaction, der rapiden schleudernden Bewegung und der Sauerstofiabwesenheit. Nachdem aber eive Reihe von Versuchen gezeigt hat, dass Pilzsporen aus der Blutbahn herausgeführt werden, dass ein durchaus guter, nicht etwa mit ausgetretenem Blute untermischter Abscesseiter enorme Mengen derselben angesammelt entbält, da kann man sich wohl kaum der Vorstellung verschliessen, das schop innerhalb der Blutbahn bei Warmblütern ein Theil der Pflanzenzellen von farblosen Blutkörperchen aufgenommen, und dem Contact mit der assimilirbaren Gewebsflüssigkeit entzogen werde. Beim Frosche habe ich sowohl im Herzblute als im Mesenterium sporenhaltige 
w. Blutkörpenchen direct beobachtet. Dass Blutserum an sich eine immerhin brauchbare Nährflüssigkeit darstellt, ist oben bereits mehrfach erwähnt, trotzdem aber dürfte es den Pilzsporen nirgends schwieriger werden, dasselbe zo itrem Wachsthum zu verwenden als in den Gefässbahnen selbst, in welchen die Verhältnisse für ihre Entwickelung noch schwieriger sind, als in der bewegten Flüssigkeit. -

Sehe ich somit den wachsthumshemmenden Einfluss der erörterten vier Momente in Bezug auf die von mir verwendeten Pilzspecies für bewiesen an, so wird es jetzt an der Zeit sein, auf die hochinteressanten und glücklichen Resultate einzugehen, welche Grohé bei der Einlührung von Pilzsporen in die Circulation von Thieren erhalten hat. Sein kurzer Bericht in No. I der Berliner klin. Wochenschrift 1870 und die als Ergänzung dienende ausführlichere Dissertation von Block ${ }^{1}$ ) enthalten Versuche, welehe mit den Gonidien frisch gezuchteter Schimmelpilze (Aspercillus gl. und Penicillium gl.) ausgefübrt waren, und welche nicht nur ein Wachsthum der Gonidien an Ort und Stelle, z. B. im Peritoneum, sondern eine Auskeimung in Blute und dadurch bedingte zahilose Metastasen in allen Organen, namentlich in den Nieren zur Folge hatten. Block giebt mehrere Abbildungen, in welchen man kurze, theilweise jedoch schon verästelte, Querscheidewand tragende Keimschläuche die Wand eines Gefässes durchbrechen siebt, dessen Lumen von Sporen bis zum völligen Verschluss angefüllt ist. Bis zu ejner Fruchtbildung ist es innerhalb der Gewebe nie gekommen, da die Thiere gewöhnlich am 4,6 . Tage und etwas später an einer Mycosis generalis zu Grunde gingen. War die Sporenflussigkeit in den Bauchraum injicirt, so fand sich das Peritoneum und namentlich das Zwerchfell äbnlich einer Miliartuberculose durchsetzt von gelben, Pilzföden enthaltenden Knötchen; ähnliche enthielten die Muskeln und Nieren.

Die Einfuhrung von Hefezellen in die Vena jugul. führte unter „foudroyanten Erscheinungen" den Tod der Thiere in längstens 24 Stínden herbej, ohne.dass hierbei Wachsthumsbeweise aufgefunden worden wären; bei Injection von Hefe in die Bauchhöhle starb das Thier erst naeh 75 Stunden.

1) Alwin R. A. Block, Inaug-Diss. 1870. Greifswald. 
Bemerkenswerth ist der Umstand, dass subcutane Injectionen von Aspg. und Penicill. und solche in die vordere Augenkammer resultatlos blieben, und dass die pralle Anfüllung der Kniegelenke mit den genannten Schimmelgonidien nur eine allgemeine Vereiterung, keine Keimung zur Folge hatte. - Mit vollstem Rechte betont Grohé die Tragweite dieser seiner Versuchsergebnisse, da die Gonidien der bejden ganz allgemein verbreiteten Pilze, welche in der Luft, dem Trinkwasser, auf den Oberflächen der Nahrungsmittel zu Milliarden vorkommen, auf die mannichfachste Weise ihren Weg auch in die Blutbahn finden, und dort eine Gesammtverschimmelung des lebenden Körpers einleiten könnten. - Unter Anderem habé ich mich ubberzeugt, dass die Sporen von Penicillium von frischen, noch nicht granulirenden Wundflächen aus resorbirt werden, und ich sehe seitdem jede frische, namentlich Flächenwunde, welche entweder ganz offen, oder wenigstens ohne Lister'schen Spray behandelt wird, als ein neues Experiment an, welches die Schlüsse Grohé's in der ausgesprochenen Allgemeinheit, wenn nicht $z u$ widerlegen, so doch erheblich zu beschränken angethan ist, da niemals eine Auskeimung der Sporen in dem Körper des Verletzten auch nur andeutungsweise beobachtet worden ist. Zwei Wege giebt es indess, welche die so entgegengesetzten Resultate der Grohéschen Versuche einerseits, der täglichen Erfahrung und der negativen Experimente andererseits, ausgleichen könuen. Entweder nehmlich wäre es möglich, dass zu den von Grohé verwendeten Schimmeln sich ein fremder, unentdeckt gebliebener Pilz eingeschlichen hätte, welcher seitdem nicht wieder aufgelunden worden ist, und der die Eigenschaften besessen haben müsste, den oben nambaft gemachten vier Hemmungswirkungen zum Trotz in der Blutbahn zu keimen. Oder ein ebenfalls unbekannt gebliebenes, zufälliges, übersehenes Ereigniss hat bei den Experimenten Grohé's staltgehabt, welches die Wirkung eines der von mir hervorgebobenen und in ibrer Bedeutung gewürdigten vier Hemmungsmomente paralysirt hat. Diese Betrachtungen würden den Werlh einer jener Nothbypothesen, welche den Beweis ersetzen sollen, nicht übersteigen, wenn sich nicht eine Anzahl von Beobachtungen im Laufe meiner Untersuchungen ergeben bätte, welche mit einer gewissen Nothwendigkeit auf jene Schlüsse hinführte.

A. Zu der ersten Möglichkeit, dass es nicht Aspergillus noch Penicillium, sondern ein anderer Pilz gewesen sein könnte, 
könnte, welcher die Kejmungen hervorgebracht hätte, beschränke ich mich auf den Hinweis auf zwei Thatsachen: Einmal giebt es Hunderte von Pilzfamilien, deren Gonidien nicht allein, sondern deren Keimsehläuche - und um solche handelt es sich ja nur in den Abbildungen von Block - einander so ähnlich sind, dass kein Mycologe sie mit Sicherheit zu trennen und zu unterscheiden vermag; zum Anderen sind Pilze, welche nach einer morphologischen Classification in eine Gruppe, ja manchmal zu einer Familic gehören, in ihren physiologischen Eigenschaften oft so sehr different, dass man es nie wagen darf aus der Formenähnlichkeit irgend einen Schluss auf die Lebensbedingungen derselben zu machen. Um ein naheliegendes und höchst schlagendes Beispiel zu wählen, so gehöreu nach dem Typus ihrer Fruchtbildung zwej Pilze in ein und dieselbe Klasse der Ascomyceten, welche die allergrössten physiologischen Verschiedenheiten darbieten, die Trüffel und der gemeine Pinselschimmel.

B. Die andere Annahme, dass durch irgend welchen Umstand der Eirfluss einer oder der anderen wachsthumshemmenden Einwirkung aufgehoben worden sei, hoffe ich dadurch zu legitiniren, dass ich den Nachweis fübre, dass eine solche Aufhebung experimentell herzustellen ist, und dass uuter solchen Verhältnissen Pilzkeimungen oft von so grosser Ueppigkeit im Thierkörper auftreten, dass sie hie und da an die Erfolge von Grohé fast heranreichen: Die die Ernährung der Pilze störende Schnelligkeit der Saftbewegung und die Anwesenbeit lebender thierischer Zellen fallt fort, wenn man die Gonidien in ein Blutgefäss und zellenloses Gewebe, in den Glaskörper des Auges einbringt. Nimmt man Gonidien von Oidium lactis, oder noch weit besser solche von dem Soorpilz nach sorgfälligster Entfernung aller grösseren Gliederzellen in eine saubere Pravaz'sche Spritze, sticht durch die Sclera und Chorioides in den Glaskörper ein, und entleert möglichst in dessen Mitte einen Tropfen der Sporerisuspension, so beobachtet man Folgendes ${ }^{1}$ ): Schon nach wenigen etwa $3-4$ stunden findet man in dem exstirpirten Auge eine Verfüssigung, oder wenigstens ein Weicherwerden des

1) Da ich aus einer grossen Zahl von Experimenten nur das Resumé gebe, so wähle ich die typischen Fälle aus und werde der vielfachen Misserfolge, resp. Wachsthumsstörungen ebenso in der Gesammtheit gedenken ohne einzelne Fälle ausführlich zu beschreibea. 
Glaskörpers ohne irgend welche merkbare Trübung. Um so überraschender ist es, wenn man die Glaskörpermasse unter das Mikroskop bringt, und in ihr eine ganze Anzahl von jungen Keimlingen enthalten findet, wie sie Fig. $1 \mathrm{a}-\mathrm{d}$ veranschaulicht. In einzelnen Fällen, z. B. bei einem Hunde, der $5 \frac{1}{2}$ Stunden nacb der Injection von Soorsporen aus anderen Grtinden getödtet wurde, waren die Pilzschläuche so üppig, und bis zu solcher Länge angewachsen, dass sie ein Gesichtsfeld bei Hartnack 7 0c. 3 eingeschob. Tubus weit überragten. Verlief der Versuch, wie bei einigen Kaninchen, ohne jegliche Reaction, so waren nach 18-24 Stunden auch makroskopisch die jungen Pilzrasen im Glaskörper zu constatiren. Bei einfacher Beleuchtung mit dem Augenspiegel gewahrte man in dern Glaskörper meist nahe der Netzhaut, oder dieser sogar lose anbaftend ein, zwei und mehrere submiliare bis miliare rein weisse Knötchen, welche unter dem Mikroskop sich als ein dicht verfilztes Convolut langgliedriger, dünner, höchstens an den Enden mit einem Knöpfchen besetzter Pilzfäden answiesen. Die Objecte glichen durchaus den Culturobjecten des Soorpilzes, welche in sehr diluirten, zuckerarmen Nährlösungen angestellt worden waren. (Siehe oben Fig. 1 d.) Weiter als bis zur Bildung solcher etwa stecknadelknopfgrosser Soorhäufchen lässt sich nach meinen Erfahrungen die künstliche Verschimmelung des Glaskörpers nicht treiben, denn nach diesern Stadium tritt ausnahmslos eine Eiterung ein, welche das ganze Auge irreparabel vernichtet. Sofern man von Zeit zu Zeit die operirten Kaninchen mit dem Augenspiegel untersucht und dabei auf den Beginn grösserer wolkiger Trübungen Acht hat, welche von den kleinen stationären Soorhäufchen unschwer zu unterscheiden sind, so wird man oft gerade dieses erste EinIreten der Eiterung für die mikroskopische Untersuchung gewinnen können. Von alleu Seiten her dringen dabei die contractilen Zellen auf den sich entwickelnden Fremdkörper ein, und umlagern inn derart, dass man nur nach vorsichtigem Ausschwemmen des Objectes, oder nach Kalizusatz überbaupt die Pilzfäden zu Gesichte bekommt. Hier ist es, wo sich dem unbefangenen Auge unabweisbar die oben beregte Analogie zwischen der Wirkung der Eiterkörperchen und jener der Bakterien auf die Keimlinge der Fadenpilze aufdrängt. Die thierischen Zellen haben offenbar hervorragend bessere Bedingungen zu ihrem Leben in dem Glaskörpergewebe, und ich habe demzu- 
folge keinen Fall gesehen, in welchem nicht sehr bald nach ihrem Erscheinen die Hyphen des Soor oder die Keimlinge des Oidium lactis abgetödtet worden und zu Grunde gegangen wären. Die entzündliche Reaction des Gewebes trat sehr viel schneller ein und die Sprossung der Fadenpilze blieb unvollkommen und rudimentär, wenn durch Zufall oder mit Absicht Mikrococcen oder Bakterien mit in den Glaskörper eingeführt waren. Die grossen Keimlinge batten hier den Kampf mit zwei Feinden zu bestehen, dem sie unbedingt unterlagen, während es zweifelhaft blieb, ob die massenhaft ausgewanderten Eiterzellen die Mikrococcenrasen erstickten, oder, wie einzelne Fälle bewiesen, die letzteren zur Resorption gelangten und allgemeine Septichämie einleiteten. Wie verschieden sich die Gonidien der letzigenannten Fadenpilze in Bezug auf ihre Wachsthumsfähigkeit gegenüber den Schizomyceten verhalten, dafür liefern einige Versuche einen Maassstab, bei welchen an einem gesunden Kaninchen eine Tridectomie gemacht wurde, und nach 24 Stunden, wenn die Verletzung obne Reaction blieb, das eine Mal Soorsporen, das andere Mal Mikrococeen durch Injection in die Bauchhöhle in die Blutbahn gebracht wurden, in der Intention, dass sie sich an jenem Locus minoris resistentiae niederlassen möchten. Für den Soorpilz blieben diese Experimente stets resultatlos, die Heilung verlief ungestört. Die Einfuhr der Schizomyceten ins Blut hatte eine eitrig jauchige Panophthalmitis mit Entwickelung massenhafter Mikrococcenrasen als unausbleibliche Wirkung zur Folge. Für andere Schimmelpilze, als Oidium lactis und den Soorpilz hat die Injection in den Glaskörper keine positiven Resultate ergeben, ich babe niemals unter den gleichen Bedingungen eine Keimung der Mucorineen oder des Penicillium wahrgenommen. - Nachdem somit für zwei Pilze, für das Oidium lactis und den Soor die Möglichkeit einer Keimung in thierischen Geweben ausser Zweifel gestellt war, unter Bedingungen, welche die Gegenwart thierischer Zellen und eine starke Bewegung ausschlossen, versuchte ich noch einmal die Einbringung jener Sporen in seröse Höhlen unter Verhältnissen, welche ebenfalls die Concurrenz lebender Gewebszellen möglichst einschränken. sollten: 1. Wurden einer Anzahl von Kaninchen ausgiebige Stücke der Iris excidirt, um die resorbirende Thätigkeit dieser Membran zu beeinträchtigen, und nach eingetretener Heilung Soorsporen in die vordere Augenkammer injicirt. Ob- 
wohl die Erfolge nicht so constant waren, wie die Injectionen in den Glaskörper, so erhielt ich doch mehrfach lange und verzweigte gegliederte Pilzhyphen, welche ebenfalls sehr wenig, meist gar nicht Seitenknospen abgeschnürt hatten, sondern wiederum nur der Wachsthunsform entsprachen, welche der Pilz in sehr nabrungsarmen Culturflüssigkeiten einzuschlagen pflegt. $\mathrm{Zu}$ wirklich makroskopisch erkennbarer Rasenbildung kam es nicht, da regelmässig, sofern Keimung eintrat, auch eine Eiterung nachfolgte, und nur dann gar keine Veränderungen sich zeigten, wenn die defecte Iris die Sporen gleich einer normalen Haut resorbirt und in die Blutbahn übergeführt hatte. In der Bauchhöhle 2. suchte ich die schnelle Resorption durch zwei Mittel hintanzuhalten. Entweder wurde den Kaninchen die Bauchhöhle durch atmosphärische Luft trommelartig aufgeblasen, und grosse Mengen von Flüssigkeit, welche Soorsporeu enthielt, injicirt, oder ich schlag einen Weg ein, den Wegner bei seineu Untersuchungen ${ }^{1}$ ) über das physiologische Verhalten der Peritonealhöhle zuerst angewandt, und der darin besteht, dass man die Anfüllung der Bauchhöble mit Luft monatelang wiederholt, und dann plötzlich alle Luft durch einen eingestochenen Troikart entweichen lässt. Die plötzlich entspannten Bauchdecken collabiren hierbei und es tritt ein Hydrops ex vacuo ein, welcher keine zelligen Elemente enthält, und daher ganz wohl die von mir gewünschten Bedingungen erfüllte. In der That war der Erfolg über Erwarten. günstig, zumal wenn jch die erste Methode der Resorptionsverhinderung mit einem Verfahren combinirte, das geeignet ist, die chemische Beschafferheit der thierischen Säfte, nach einer fur das Pilzwachsthum vortheilhaften Richtung zu alteriren. Zugleich mit dem starken Aufblasen der Bauchhöhle mit Luft machte ich nehmlich den Thieren eine subcutane Injection von Amylnitril, wodurch bekanntlich tür etwa 24 Stunden ein künstlicher Diabetes mellitıs erzeugt wird. Unter diesen Bedingungen wurden einer Anzahl Kaninchen entweder an demselben Tage, an welchem ihnen eine Amylnitritinjection von 5 bis 7 Theilstrichen einer Pravaz'schen Spritze beigebracht war, oder erst am folgenden, wenn der aufgesammelte Harn schon stark reducirende Wirkung angenommen hatte, sorg-

1) Georg Wegner, Chir. Bemerkungen über die Peritonealhöhle. Langenbeck's Arch. 1876 , 
fältig colirte Soorgonidien in die Bauchböhle eingeführt. In der Regel überlebten die Thiere den Eingriff zwei bis drei Tage, dann starben sie, nachdem der Harn keinen Zucker mehr hatte erkennen lassen, unter den Erscheinungen starker Dyspnoe und Lungenödems. Bei der unmittelbar nach dem Ableben angestellten Section fand sich das Bauchfell übersät mit miliaren bis stecknadelknopfgrossen gelben festbaftenden Herdchen, welche besonders zahlreich in dem Ueberzug des Zwerchfelis steckten, aber auch in jenem der Eingeweide selbst nicht fehlten. Die mikroskopische Untersuchung dieser Herde wies für die meisten, namentlich für diejenigen des Zwerchfells nach, dass es sich um Anfüllung der Lỵmphgefässe mit jungen, oft sehr üppig gewucherten Keimschläuchen bandelte, um welche herum eine Ansammlung von Rundzellen stattgebabt hatte, welcher die Knötchen offenbar ihre Aehnlichkeit mit in Verkäsung begriffenen Miliartuberkeln verdankten. Neben diesen schon vom blossen Auge erkennbaren Herden ergab die mikroskopische Durchmusterung zahllose weitere Stelten, in welchen die Lymphgefässe um einen oder einzelne gekeimte Sporen Rundzellen mit einem oder zwei Kernen enthielten, welche von Strecke zu Strecke varicöse Erweiterungen der Lymphbahnen bewirkten. Vielfach sah ich ganz junge Keimscbläuche in einem grösseren Lymphgefäss liegen, welche nocb keine Zellenansammlung zur Folge gebabt hatten, in deren Bereich aber die platten Endothelzellen einem körnigen, zum Theil feltigen Zerfall unterlegen waren. Andere Hepde endlich, namentlich grössere, kamen vor, in welchen bei aufmerksamstem Nachsuchen keine Pilzfäden innerbalb der Rundzellen aufgefunden werden konnten, obgleich ihr Aussehen und ihr Sitz sich in nichts von den ersteren unterschied. Dass es sich in diesen Fällen um die nehmliche Entstehungsweise handelt, dürfte kaum eine Beanstandung erfahren, nachdem sowohl die Züchtungsversuche der Pilze zugleich mit Schizomyceten als auch die Impfungsresultate im Glaskörper erwiesen haben, dass Pilzfäden durch lebende Zellen ertödtet, sehr leicht aufgelöst werden und verschwinden können. Den Ort der Knötchenbildung anlangend wurde bereits bemerkt, dass nur die abdominale Oberfläche des Zwerchfells deren enthielt, und auch für diejenigen Herde, welche sich in dem sogen. visceralen Blatte des Peritoneums entwickelt hatten, und auf der Oberfäche des Darms und der Leber erschienen, blieb die Veränderung auf den serösen Ueberzug 
dieser Organe beschränkt. Nur eine Ausnahme von diesem Verhalten habe ich zu registriren, welche bei einem mit Luftaufblasen und Amylnitrit vorbereiteten Kaninchen nach Soorinjection auftrat: In diesem Falle wurde am 6. Nov. 1875 eine subcutane Injection von 0,16 Amylnitrit gemacht; am 7. Nov. enthielt der Harn sehr .reichlichen Zucker und jetzt wurde die Sporenflüssigkeit zugleich mit einẹr Menge von Luft in die Bauchböhle eingebracbt. Noch am 8. Nov. war der Harn stark zuckerhaltig. Am 9. Nov. war die Reaction zweifelhaft, das Thier ziemlich munter, nur bestand heftige Diarrhoe. Am 10. Nov. erfolgte der Tod, und es fanden sich erstens das Diaphragma voller gelber Pilzherde, ebenso andere Stellen des Peritoneum und mehrere ganz gleich beschaffene graugelbe Knötchen von Stecknadelknopfgrösse schimmerten durch die Serosa der Leber hindurch. Von einem der letzteren gelang es nach voraufgegangener Härtung in Alkohol absol. Schnitte anzufertigen. Die Kapsel der Leber war völlig aufgegangen in einen mit zerfallenen Zellen gefüllten Herd, welcher eine grosse Menge junger Keimlinge und sehr lange Fäden enthielt, welche sich durch die angrenzenden körnig und fettig zerfallenen Leberzellen bis in die Nachbarzone vorschoben, woselbst sie mit ihren äussersten Spitzen zwischen die grossen noch wohl erhaltenen Leberzellen vorragten. Eine reactive Eiterung war hier nicht erfolgt. -

Un dem Einwande za begegnen, als sei bei der vorgeführten Versuchsreihe weniger die behinderte Resorption als die chemische Einwirkung des Amylnitrits die wesentliche Ursache der Pilzentwickelung, so sei hier statt vieler ein Parallelversuch erwähnt, welcher an ein und demselben Tage mit drei Kaninchen unter Anwendung derselben Sporenlösung angestellt wurde: Das eine der Thiere erhielt eine Sporensuspension von Oidium lactis in Menge von etwa $10 \mathrm{ccm}$. in die Bauchhöhle eingespritzt ohne jegliche Combination. Das zweite ebenso behandelte Thier ausserdem 0,09 Ccm. Amylnitrit unter die Haut; das dritte die gleiche Menge von Pilzsporen, kein Amylnitrit, sondern bis zur straffen Spannung Luft in die Baucbhöhle. Die beiden ersten Kaninchen überstanden den Eingriff ohne Schaden, nur das dritte ging nach 48 Stunden zu Grunde, und liess bei der Section zahllose miliare Pilzherde in dem Peritoneum erkennen.

In Uebereinstimmung mit den Experimenten am Glaskörper 
erwies sich auch unter den günstigsten Bedingungen die Einbringung von Sporen anderer Pilze, Mucor, Penicillium, Aspergillus als constant fruchtlos. Andererseits verlor jch bei keinen Versuchen so viele Thiere an Septichämie, als bei diesen, da trotz aller Vorsicht die Miteinspritzung von Mikrococcen nicht absolut vermieden werden konnte, und diese einen so günstigen Boden für ibre Keimung fanden, dass entweder eine acute Sepsis oder eine durch sie bedingte Peritonitis die Thiere tödtete, ehe die Sprossungen der grösseren Pilze über die Production kurzer verkümmerter Aussendlinge vorgeschritten war, welche dann inmitten der Eiterzellen abgestorben vorgefunden wurden.

Die übrigen Körperorgane liessen keine constanten Veränderungen bemerken; sobald die Sporen in die Blutbahn gelangt waren, verfielen sie auch trotz des Diabetes dem Untergang; in den reinen, nicht durch Mikrococcen gestörten Versuchen deutete das regelmässig vorbandene Lungenödem darauf hin, dass hier die localen Störungen des Zwerchfells eine Lähmung dieses Muskels und hiermit die directe Todesursache herbeigeführt hatte.

Die Methode, durch plötzliche Entspannung der vorher ausgedehnten und erschlafften Bauchdecken die Resorption zu verhindern, wurde consequent nur in einem Falle durchgefïhrt, and in diesem Soorsporen ohne Anylnitrit verwandt. Das Zwerchfell dieses Thieres enthielt nur sehr wenige und kleine Herde, dagegen hatten sich in zwei sclerotischen Platten, deren eine sich durch die lange -Spannung an der grossen Curvatur des Magens, deren andere sich in der Milzkapsel gebildet hatte, zwei Soorhaufen etablirt, welche den Umfang einer kleinen Linse erreichten, und an Länge und Ueppigkeit der Fäden den bei Kindern in der Mundhöhle vorkommenden gewiss nicht nachstanden. Das Thier war durch Carotidenöffnung am 3. Tage getödtet worden.

Diese positiven Versuchsresultate beweisen noch weit zwingender, als die Schlüsse aus den früheren negativen Ergebnissen, dass jedem der oben aufgestellten 4 Hinderungsmomente der Pilzkeimung, 1) der Alkalescenz, 2) der Bewegung, 3) dem Mangel an freiem Sauerstoff und 4) der Gegenwart lebender thierischer Zellen seine volle onverkürzte Bedeutung bei der Beurtheilung des parasitären Wachsthums zukommt.

Wir sehen, dass bei Aussehluss von 2 und 4 and ebenso bei 
Ausschaltung von 3 und 4 Gonidien niederer Pilze in Säften und Geweben von Warmblütern wuchern, und dass sie derartig intensive Einwirkungen setzen können, dass durch sie der Tod des Individuums bedingt wird. Unzweifelhaft ist der 4 . Factor der wichtigste: In dem Glaskörper, in der vorderen Augenkammer, in den Lymphwegen der Bauchhöhle geht die Pilzentwickelung nur so lange ibren ungestörten Gang, bis durch den erhöhten localen Reiz eine Wucherung junger Zellen entweder von den betroffenen Geweben selbst, oder von den nächst angrenzenden Nachbartheilen geliefert wird. Hiermit ist den vegetabilischen Zellen sofort jede weitere Ernäbrung abgeschnitten, sie gehen unfehlbar zu Grunde. Es ist nur ein scheinbarer Widerspruch, wenn wir in den Pilzherden der Leber die langen, frischen Soorfäden durch die Leberzellen durchdringen und diese letzteren in körnig fettigem Zerfall begriffen fanden. Auch hier müssen die ersten Auskeimungen iu den Lymphgefässen der Leberserosa stattgefunden haben; da hier keine Zellenproliferation erfolgte, erreichte das Mycelium eine solche Ueppigkeit, dass es von dem Orte seiner eigentlichen Ernährung immer weiter vordrang, und nun seinerseits eine solche Raumbeschränkung für die Leberzellen setzte, dass diese selbst zu Grunde gingen, noch ehe eine Proliferation junger Zellen den fremden Eindringlingen Halt gebot. Die Leberzellen verhalten sich in dem beregten Falle augenscheinlich äbnlich torpide, wie die dicken Epitbellagen der Schleimbäute oder des Rete Malpighi der äusseren Haut gegenüber dem Vordringen eines Pilzes, dessen Wurzellager bereits an einer anderen Stelle festen Fuss gefasst hat, und von hier aus den Vorposten reichliche und kräftige Nahrung zu ihrem Kampfe zuschicken kann.

Für die beiden Familien des Oidium lactis und des Soorpilzes genügt die Aufhebung des 4. Momentes, combinirt mit dem Wegfall von starker Bewegung allein, um an dem Orte der Aussaat eine mehr oder weniger reichliche Wucherung hervorzurufen. Die höheren Pilze, vor allen Aspergillus und Penicillium gl. sind wenigstens unter den von mir versuchten Bedingungen, deren ich eine ganze Anzahl Modificationen fruchtlos unternommen, nie zum Keimen gekommen, sofern nur noch der eine Factor der Alkalescenz, der überhaupt nicbt zu eliminiren ist, übrig blieb. Sei es dass die Resorption des Bauchfells sich früher regulirte, ehe die Gonidien zum Sprossen gekommen waren, sei es, dass die ungünstige Nahrung sie gegen 
die mässige Bewegung des Saftstromes noch empfindlicher machte, dass die immerhin für ihre Vegetation ungewohnt hohe Temperatur oder unbekannte chemische Einflüsse (welche den Säften nur intra vitam zukommen müssten) sie am Wachsen hinderten, - es ist mir niemals gelungen, eine Verschimmelung innerer Organe durch Aspergillus zu beobachten, und ich komme wieder auf meine Behauptung zurück, dass bei den Experimenten Grobe's, - die Identität der Keimschläuche mit Aspergillus vorausgesetzt - ein unbeachtet gebliebenes Agens eingewirkt baben muss, das eine wahrscheinlich chemische Decompasition der Gesammtsäfte berbeigeführt, und damit auch für die höheren Pilzarten in der Blutbahn und deo Körperorganen einen Nährboden für Schimmelbildung hergestellt hat. Ohne eine solche fremde Substanz bleibt es unerklärlich, wie die Infusionen von Hefe, welche doch eines Zuckergehaltes zur Entfaltung ihrer gährungserregenden Eigenschaften bedürfen, den Tod der Thiere unter stürmischen Erscheinungen herbeiführen konnten, und besonders auffallend ist es, dass nur die Injection grösserer Mengen von Sporen einen Erfolg batte, während in der vorderen Augenkammer, in den Gelenken und dem Unterbautfettgewebe die Sporen entweder wirkungslos blieben, oder Eiterung ohne vorhergegangenes Wachsthum verursachten. Welcher Art djeses Agens gewesen sein mag, ist natürlich nicht zu entschleiern, indess wäre es möglich, dass der hier angezeigte Weg, welcher für $z$ wei andere Pilzfamilien Ernährungsmöglichkeiten innerbalb des lebenden Organismus aufgefunden hat, auch zur Wiederentdeckung eines Factors führte, welcher die Alkalescenz und die Lebensthätigkeit der Blutzellen ausser Kraft zu setzeu vermöchte. Es würden damit dje Resultate von Grohe zwar ibrer verbängnissvollen Bedeutung entkleidet, aber Gesichtspunkte und Möglichkeiten für experimentelle Forschungen erschlossen werden, unter denen solche über die secretorische Thätigkeit der Nieren, welche unversehrt Pilzsporen in den Harn befördert, nicht die letzte Stelle einnehmen würden.

Zum Schluss verdient nun noch die Frage eine kurze Erörterung, ist die zerstörende Wirkungsweise der parasitisch in Geweben lebenden Fadenpilze eine mechanische oder chemische? Die Beobachtung, dass Pilzhyphen in die Zahnsubstanz eindringen können. woselbst sie dann in Kanälen von unregelmässigem Verlauf, welcht 
durehaus unabhängig von den normalen Kanälchen dieser Substanz sind, aufgefunden worden sind, diese Beobachtung deatet mit viel Wahrscheinlichkeit darauf hin, dass hier eine chemische Auflösung der Zahnmasse, bedingt durch den Wachsthumsprozess des Pilzes, Platz greift, wodurch der Raum für die Mycelfäden mühsam Schritt für Schritt erworben werden muss. Da ich selbst Objecte dieser Art nicht untersucht habe, so bann ich über den Vorgang der Auflösung nichts Zuverlässiges aussagen; wenn es erlaubt ist, an eine Analogie zu erinnern, so hat man Wurzelfäden höherer Pflanzen auf polirten Marmorplatten sich ausbreiten lassen, und gefunden, dass die von den Wurzelharen abgegebene Kohlensäure so viel Kalk in Lösung bringt, dass die Marmorplatte nach einiger Zeit einen prächtigen Aetzabdruck aller Wurzelverzweigungen erkennen lässt. Unter den Folgezuständen, welche ich bei meinen Experimenten im Verlaufe des Pilzwachsthums intra vitam wabrgenommen habe, finde ich keinen, welcher auf eine chemische Wirkung der Pilze bezogen werden könnte. Die Verflüssigung des Glaskörpers ist keinenfalls abhängig von dem Lebèsprozess der in ihm gezuchteten Mycelfaden, da einerseits so grosse Pilzrasen inmitten seiner Substanz bestehen können, dass sie einer makroskopischen Diagnose zugänglich sind, ohne jene Verfluissigung zu bedingen, und da andererseits jede von Pilzen unabhängige acute Entzündung und namentlich Eiterung der Chorioides dieselbe Erscheinung auslöst. In einem Falle, in welchem Soorsporen in die vordere Augenkammer injicirt worden, war der schräge Stichkanal der Cornea vollkommen ausgefüllt mit einem dichten Baumwerk von langen Pilzfäden; die angrenzenden Gewebstheile zeiuten dabei keine stärkere Vergrösserung der Hornhautkörperchen als um jeden anderen Stichkanal herum, die homogene Zwischensubstanz verhielt sich völlig reactionslos, so dass eine chemische Zersetzung von irgend welcher Bedeutung wohl mit Bestimmtheit ausgeschlossen werden darf. Die ersten Anfänge der Knötchenbildung in den Lynuphgefässen des Bauchfells ergaben sich als Verstopfungen der Gefässbahn durch Keimschläuche; zugleich mit der localen Ausbuchtung des Gefässchens fand sich ein körniger, später fettiger Zerfall der Endothelzellen, eine Metamorphose, wie sie ganz gewöhnlich im Gefolge einer mechanischen Druckwirkung stattufinden pflegt. Dasselbe gilt von dem Zerfall der Epithelien der Wurzelscheide eines mycolisch 
erkrankten Haarfollikels, dasselbe von der körnigen Trübung, welcher in dem oben citirten Falle die Leberzellen unter dem Vordringen der dichten Pilzvegetation unterlegen sind. Ist der Untergang der Zellen durch das mechanische Andringen des Parasiten, zum Theil auch wohl durch die Nahrungsentziehung, welche er ausibbt, erfolgt, so bilden die todten Zellenleiber für ihn eine durchaus günstige Nahrung, und der Vorgang der Assimilation unterscheidet sich nunmehr in keiner mit unseren Mitteln erkennbaren Weise von dem Lebensprozesse der saprophytischen Pilze.

\section{Erklärung der Abbildungen.}

Tafel XVIII-XIX.

Fig. 1. Der Soorpilz. a Einzellige, b und c mehrzellige Keimlinge selir st. Vgr. d I In dünnen Nährlösungen gezüchtetes ästiges Mycelium mit wenigen Seitenknospen. e Kurzgliedriges mit vielen Knospen besetztes Mycelium. f $\alpha$ Hefestadium. if $\beta$ Mycelstadium des Soorpilzes.

Fig. 2. Der Favuspilz. a Keimscbläuche in Gelatinelösung gezüchtet. b Scheidewandführende Mycelien, welche in dünnen sauren Lösungen zu langen Fäden auswachsen. c Keimschlauch, welcher (in concentr. Nahrung) in einzelne Gonidienglieder zerfallen ist. d Solche, noch in ihrem Verbande befindlichen Glieder angekeimt. e Fruchtbildung. e $\alpha$ Beginnende Bifurcation an den Fadenenden. $\beta$ Knospenbildung. $\gamma$ Gemmenbildung. $\varepsilon$ Leere Fadenschläuche. $\zeta$ Verschiedene Modificationen der Theilung und Gonidienbildung. f Pilzfäden aus dem durch Favusimpfung hervorgebrachten berpetischen Vorstadium genommen. 1 : 350.

Fig. 3. $\alpha$ Keimung von Gonidien des Pityriasispilzes. $\beta$ Dänne protoplasmaarme Fäden, mit vielen Vacuolen, wie sie den Fäden des in diluirten Nährlösungen cultivirten Pityriasis- und dem Herpespilze (Paradigma III) eigenthümlich sind. $1: \mathbf{3 5 0}$.

Fig. 4. a Herpespilz von Epidermisschuppen einer Kuh in neutraler Gelatinelösung gezüchtet. Die Fäden sind kurz, zerfallen sehr schnell in ihrer Totalităt in kurze Gliederabschnitte, welche sehr. verschieden lang und üppig sind. Bei $\alpha$ Gemmenbildung. Sehw. Vergr. LV. III. b Gonidien von Oidium lactis, aus denen unverbăltnissmässig dünne Keimschläuche (in diluirter saurer Nabrang) hervorgewachsen sind. Dieselben haben an ihrem anderen Ende Gonidien abgeschnürt, welche kaum die Grösse der Fig. 4 a abgebildeten Herpesgonidien erreichen, $c$ Einzelne wenige Mycelfäden von dem Herpes (Paradigma II) mit Fructification. a Lufthypben. 1:300.

Vergleiche hiermit die Abbildungen von Bärensprung in den Charité-Annalen 1855, welche nicht cultivirten, sondern frischen objecten entoommen sind, und eine vollkommene Uebereinstimmung mit den meinigen innerhalb derjenigen Grenzen zeigen, welche durch die Verschiedenartigkeit der Nährsubstrate bedingt und erklärt sind. 